\title{
POLÍTICA DE FORMACIÓN PARA LA INVESTIGACIÓN, LA INNOVACIÓN Y EL EMPRENDIMIENTO
}

MARCELA IREGUI GUERRERO JUAN MARÍA CUEVAS SILVA

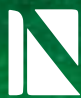

Editorial Neogranadina 


Política de formación para la investigación, la innovación y el emprendimiento (FIIE) 



\section{Política de formación para la investigación, la innovación y el emprendimiento (FIIE) \\ Marcela Iregui Guerrero Juan María Cuevas Silva}

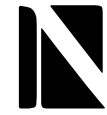

Editorial

Neogranadina

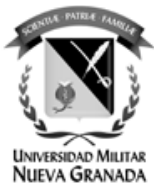


Política de formación para la

investigación, la innovación y el

emprendimiento

Colección Literatura Gris,

serie White Papers UMNG · Número 1

(C) Universidad Militar Nueva Granada,

Vicerrectoría de Investigaciones

(C) Marcela Iregui Guerrero y Juan María Cuevas Silva

(C) Editorial Neogranadina

Primera edición, 2018

ISSN digital: 2665-1920

ISSN impreso: 2665-1939

Editorial Neogranadina

Vicerrectoría de Investigaciones

Universidad Militar Nueva Granada

Sede Campus, Edificio de Posgrados, primer piso

Kilómetro 2, vía Cajicá-Zipaquirá, costado oriental

Teléfono: 6500000 ext. 3092

editorial.neogranadina@unimilitar.edu.co

Diagramación

Henry Ramírez Fajardo

Cómo citar:

Iregui Guerrero, M., y Cuevas Silva, J. M. (2018).

Política de formación para la investigación, la innovación y el emprendimiento. Bogotá:

Editorial Neogranadina.

Fecha de recepción: 15 de marzo de 2018

Fecha de aprobación: 7 de mayo de 2018

Fecha de publicación en línea: 8 de noviembre de 2018

DOI: https://doi.org/10.18359/whitepaper.3750 


\section{Contenido}

1. Presentación 11

2. Ejercicio de diagnóstico 15

3. Fundamentos 43

4. Objetivos de la política FIIE

5. Habilidades, competencias y desempeños por desarrollar con la política FIIE $\quad 81$

6. El currículo: escenarios estratégicos y líneas de acción $\quad 89$

Bibliografía 135

$\begin{array}{ll}\text { Agradecimientos } & 143\end{array}$ 



\section{Figuras}

Figura 1. Actividades realizadas en el autodiagnóstico de los grupos de interés, correspondientes al año 2017

Figura 2. Número de los estudiantes participantes

por programa

Figura 3. Propuestas para incentivar la investigación formativa

Figura 4. Competencias que se desarrollan

en la asignatura Metodología de la Investigación, según los docentes de humanidades

Figura 5. Competencias menos desarrolladas, según algunos docentes y directores

Figura 6. Cómo fomentar la investigación formativa según los docentes y directores de diversos programas

Figura 7. Cómo fomentar la investigación formativa según algunos docentes de la Facultad de Educación y Humanidades

Figura 8. Esquema de la política FIIE 41

Figura 9. Fundamentos de la política FIIE 44

Figura 10. Habilidades, competencias y desempeños desde las dimensiones del currículo SABE

Figura 11. Funciones curriculares de la educación superior 
Figura 12. Acciones según la línea estratégica del microcurrículo

Figura 13. Acciones según la línea estratégica del mesocurrículo

Figura 14. Acciones según la línea estratégica del currículo formación complementaria y otras estrategias

\section{Tablas}

Tabla 1. Número de estudiantes participantes

Tabla 2. Asistentes graduados participantes

Tabla 3. Número de participantes según

programa y Facultad

Tabla 4. Número de participantes según

Facultad y cargo

Tabla 5. Metodologías de aprendizaje

Tabla 6. Competencias y habilidades

relacionadas con la política FIIE

83

Tabla 7. Formulación curricular

Tabla 8. Educación disciplinaria vs. educación transdisciplinaria

Tabla 9. Objetivos específicos según

el escenario estratégico 


\section{Presentación}

La Universidad Militar Nueva Granada (UMNG) es una institución de educación superior acreditada en alta calidad, que fomenta la investigación para formar profesionales integrales, sólidos académicamente y con un profundo sentido de la ética y la responsabilidad social.

En un sentido estricto, la investigación en la UMNG persigue un doble objetivo: busca generar y construir nuevos conocimientos para que sean aplicados y tengan repercusiones sociales y, al mismo tiempo, da los cimientos del proceso de formación profesional. Aquí se presentan dos realidades de la investigación. La investigación científica, con un énfasis en la producción y la construcción del 
conocimiento, y una investigación relacionada con la formación profesional, que da las herramientas para investigar y lo que es más importante, suscita el interés continuo por renovar el conocimiento.

La Vicerrectoría de Investigaciones, reconociendo los mandatos consignados en el Plan Rectoral (2015), el Proyecto Educativo Institucional (2009) y el Plan de Desarrollo Institucional (2009-2019), ha asumido la tarea de recoger las percepciones que se tienen sobre la formación para la investigación en la UMNG. Primero, se hizo un ejercicio de diagnóstico sobre el estado de tal formación, el emprendimiento y la innovación. Segundo, como resultado de la autoevaluación del diagnóstico, surgió la necesidad de construir una política institucional que fortalezca y fomente la formación para la investigación, la innovación y el emprendimiento, a partir de los elementos curriculares de los que dispone la Universidad.

La política de formación para la investigación, la innovación y el emprendimiento ${ }^{1}$ es el producto de una serie de acciones que van desde la revisión documental hasta la ejecución de actividades participativas con distintos grupos de interés de la Universidad. Con el aval de la Rectoría, la Vicerrectoría de Investigaciones ejecutó diversas mesas de trabajo, en las cuales se definieron los

1 En adelante, política FIIE. 
principales puntos que componen la política. Este ejercicio participativo fue seguido por la construcción de un grupo asesor, conformado por la Vicerrectoría de investigaciones y por diferentes profesores, que ayudaron a consolidar la información y a darle un horizonte institucional a la política.

La política FIIE está basada en desarrollos teóricos y académicos que diferencian la investigación formativa de la formación para la investigación, la innovación y el emprendimiento. Resignificar el proceso de formación del profesional, con base en los principios institucionales y orientado desde los resultados de la participación de los distintos estamentos de la universidad, ha permitido que se formule un currículo propio, denominado SABE, el cual tiene como dimensiones lo sociológico, antropológico, bioético y epistemológico. Así mismo, se hacen apuestas en la transformación de las prácticas educativas y formativas neogranadinas, donde el currículo es el escenario estratégico: macrocurrículo, mesocurrículo, microcurrículo y currículo de formación complementaria ${ }^{2}$.

La apuesta de formar para la investigación es un reto, una necesidad y una realidad, razón por la cual esta política no es una apuesta dogmática, cerrada y terminada, sino

2 En esta política, el extracurrículo es concebido como currículo de formación complementaria. 
que, por el contrario, es una apuesta dinámica, abierta y en constante construcción. Los lineamientos establecidos en esta política son posibles siempre y cuando nos demos la oportunidad de pensar nuestra UMNG con espíritu, mentalidad, cultura y acción en la que todos quienes hacemos parte de ella, tengamos claro el horizonte de presente y de futuro, de trabajo cooperativo y colaborativo, de la flexibilidad y apertura a los cambios, todo con el fin de formar y ser ciudadanos socialmente responsables con la patria, desde la ciencia y en la familia. 


\section{Ejercicio de diagnóstico}

Durante agosto de 2017, la Vicerrectoría de Investigaciones de la Universidad impulsó las actividades, las estrategias y los instrumentos para la construcción de un diagnóstico sobre la investigación formativa en la universidad. Las actividades se desarrollaron con estudiantes, decanos, vicedecanos, docentes de tiempo completo, directores de programa y directores de centros de investigación, de las sedes de Calle 100, Campus en Cajicá y la Facultad de Medicina. Este ejercicio recogió experiencias, perspectivas y puntos de partida y mostró las diferentes caras de la investigación formativa en la UMNG. 
A continuación, se hace un recuento de los resultados de las actividades realizadas con cada grupo de interés. A partir de esos resultados, se clasificaron las necesidades, según su grado de prioridad, en un lapso de tiempo. Esas necesidades orientaron el ejercicio participativo en la construcción de la política.

\subsection{Metodología}

Las actividades del ejercicio de diagnóstico tenían como fin identificar necesidades de la UMNG en términos de la investigación formativa. Para esto, se utilizaron herramientas metodológicas cualitativas, sobre la percepción de varias fuentes y bajo ejercicios estrictos de participación abierta por parte de todos los grupos poblacionales. Estos grupos fueron conformados por estudiantes de pregrado de diversos semestres, asistentes graduados, decanos y vicedecanos de todas las Facultades y sedes, docentes de diversas Facultades, directores de programa y directores de centros de investigación. También se contó con la participación de la Vicerrectoría Académica y la Oficina de Acreditación de la UMNG. Se utilizaron dos herramientas metodológicas cualitativas básicas: los grupos focales y las entrevistas semiestructuradas, que permitieron recolectar datos de diversos actores, tanto grupal como individualmente, sin importar las diferencias que pudieran 
hacer heterogéneo el total de la población escogida para realizar esta investigación.

Se realizaron grupos focales con los estudiantes y con asistentes graduados, entre quienes se discutía sobre el papel de la investigación en sus carreras, en semilleros de investigación, y se podía debatir en torno a las fortalezas y las debilidades de la investigación formativa en su proceso de formación como profesionales. Se utilizó una variación de los grupos focales para trabajar con docentes y directores de programa y de centros de investigación. Para ellos, en vez de propiciar un escenario inmediato de discusión grupal, fue diseñada una herramienta para que, en grupos, pudiesen determinar un set de respuestas a preguntas predeterminadas y discutir al final los resultados, contrastando las respuestas sobre la investigación formativa desde su perspectiva. Las modificaciones que se realizaron para estos grupos focales estuvieron inspiradas en otras herramientas metodológicas, como la lluvia de ideas y las rutinas de pensamiento, que permiten llegar a conclusiones construidas de forma colectiva.

También se aplicaron entrevistas semiestructuradas, lo que implicó un ejercicio más profundo en términos de la exploración específica de temas. Las preguntas compuestas por la guía de la entrevista semiestructurada, aquí llamadas "preguntas-eje", funcionaron como ejes temáticos propositivos, de tal forma que la persona entrevistada 
pudiera darle forma a su intervención de la forma más natural posible y con el menor redireccionamiento por parte del entrevistador. Aquí, la oportunidad metodológica residió en el hecho de que la entrevista se realizó simultáneamente a decanos y vicedecanos, de quienes se pretendía obtener una mirada más global sobre la investigación formativa en conjunto dentro de sus Facultades. La presencia de los dos interlocutores permitió la verificación de datos entre ellos, así como una constante complementariedad en las opiniones dadas.

Con la exposición de la metodología y de sus actividades e instrumentos, se muestran, a continuación, los resultados y hallazgos.

\subsection{Resultados generales}

Durante la investigación de campo, se realizaron en total 35 actividades y participaron 266 personas de distintas dependencias y cargos, en sesiones que aproximadamente oscilaron entre 50 y 70 minutos por cada actividad. Todas las actividades fueron registradas en audio, con el fin de facilitar el posterior análisis de los datos.

En primera instancia, se expondrán los resultados obtenidos según los grupos poblacionales, respetando la heterogeneidad representada por cada grupo. Esto facilitará la observación de las particularidades y los puntos 
de encuentro que existen entre los grupos, lo cual guiará este informe -de una forma más clara- a la identificación de las necesidades.

Figura 1. Actividades realizadas en el autodiagnóstico de los grupos de interés, correspondientes al año 2017

Jornada de autodiagnóstico de la formación para la investigación en la UMNG

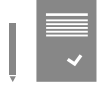

32 actividades

Estudiantes

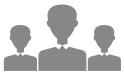

12 actividades
Se realizaron un total de 32 actividades participativas con la comunidad académica de la UMNG, Sede Campus, Sede Calle 100 y Facultad de Medicina

Asistentes graduados

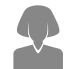

12 actividades

Decanos $y$

157Participantes

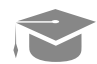

2 actividades

19 Participantes
Docentes y directores de programa

6 actividades

a. Estudiantes

Se realizaron en total 12 actividades con 157 estudiantes de las Facultades, los programas y las sedes (tabla 1 y figura 2). 
Tabla 1. Número de estudiantes participantes

\begin{tabular}{|c|c|c|}
\hline Facultad & Programa & Número de participantes \\
\hline Faries & RRII & 26 \\
\hline \multirow{3}{*}{$\begin{array}{l}\text { F. de C. } \\
\text { Económicas }\end{array}$} & Admón. de Empresas & 5 \\
\hline & Economía & 2 \\
\hline & Contaduría Pública & 2 \\
\hline F. de Derecho & Derecho & 33 \\
\hline \multirow{6}{*}{$\begin{array}{l}\text { Facultad de } \\
\text { Ingeniería }\end{array}$} & Ing. Civil & 39 \\
\hline & Ing. Ambiental & 1 \\
\hline & Ing. Biomédica & 2 \\
\hline & Ing. Industrial & 2 \\
\hline & Ing. en Multimedia & 5 \\
\hline & $\begin{array}{l}\text { Ing. en } \\
\text { Telecomunicaciones }\end{array}$ & 1 \\
\hline $\begin{array}{l}\text { F. de Ciencias } \\
\text { Básicas }\end{array}$ & Biología & 26 \\
\hline $\begin{array}{l}\text { F. de Medicina } \\
\text { y C. de la } \\
\text { Salud }\end{array}$ & Medicina & 13 \\
\hline \multicolumn{2}{|l|}{ Total } & 157 \\
\hline
\end{tabular}




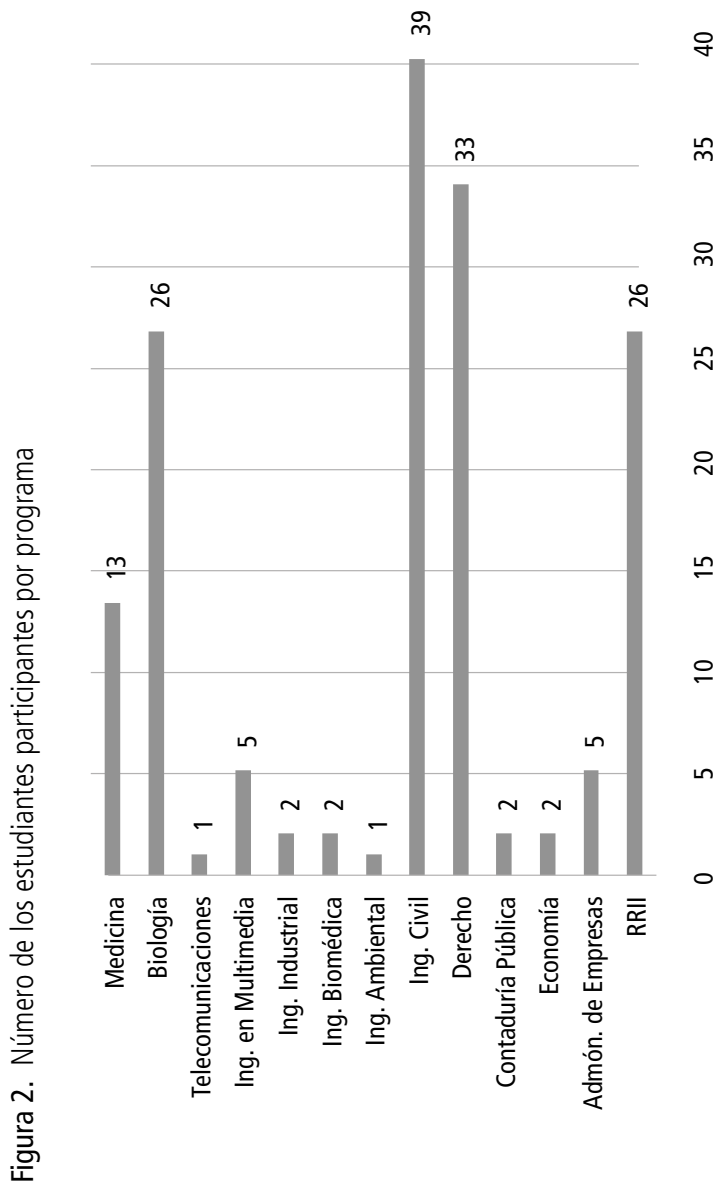

Ejercicio de diagnóstico 21 
Los resultados de este grupo se categorizaron así:

- Nociones de la investigación. Los estudiantes, en general, no se sienten atraídos hacia la investigación, debido a dos factores. El primero consiste en que no tienen claro qué significa realizar investigación (ni dentro, ni fuera del aula), y asocian esta práctica a una actividad adicional a su proceso de formación, es decir, prácticamente como un camino para ejercer la docencia en el futuro. El segundo factor es una combinación de la falta de motivación por parte de los docentes, para que los estudiantes realicen ejercicios relacionados con la investigación formativa, y un desconocimiento acerca de las oportunidades y los espacios que brinda la investigación formativa. Esta última reflexión proviene, principalmente, de los estudiantes de carreras afines a las ciencias sociales y ciencias económicas.

- Participación en semilleros. Los semilleros se presentan, para la mayoría de los estudiantes, como espacios aislados y, en ocasiones, reservados a estudiantes "más dedicados". Antes que ser vistos como escenarios de formación, los estudiantes entienden los semilleros de investigación como una de las opciones de grado con la que cuentan. Esta percepción es transversal a la opinión de todos los estudiantes de los distintos programas. 
- Asignatura Metodología de la Investigación. Los estudiantes tienen una opinión dividida acerca de esta asignatura, en dos posturas: una apoya la idea de que la asignatura siga siendo dictada por la Facultad de Educación y Humanidades; otra solicita que quede en manos de sus Facultades, para obtener mayor énfasis disciplinar. En el marco real de este debate se concluye que los estudiantes tienen una visión particular de esa asignatura, pues la consideran como la materia responsable de infundir y desarrollar la investigación formativa en las carreras. Una vez el debate se disuelve, los estudiantes acuerdan que el desarrollo de sus competencias en investigación formativa no puede depender únicamente del espacio de una asignatura. Esta opinión fue compartida por estudiantes de todos los programas.

- Transversalidad de la investigación formativa. Como producto de la discusión anterior, los estudiantes hicieron un llamado a la Universidad para que la investigación formativa haga parte de sus carreras, de un modo más transversal. Según ellos, esto es posible con un esfuerzo de los docentes, que consistiría en dar un giro a sus asignaturas e incluir la investigación formativa como método de enseñanza principal.

- Promoción de semilleros. Los estudiantes afirman que no están estandarizadas las vías a través de las 
cuales se enteran de los semilleros. Entre ellas, el "voz a voz" juega un papel importante, pero es insuficiente para conocer los semilleros, su función, su funcionamiento y, por último, sus requisitos de ingreso u otras dinámicas. Esto, sumado a la falta de claridad en las nociones sobre la investigación y la falta de motivación que se recibe por parte de los docentes, hace que los estudiantes pierdan el interés en la investigación.

- Interdisciplinar y multidisciplinar. Los estudiantes piden que se aproveche el esfuerzo de incentivar la investigación formativa como una oportunidad para promover el trabajo entre Facultades, especialmente bajo la lógica de la transversalidad.

b. Decanaturas y vicedecanaturas

En total, se realizaron 12 entrevistas a 12 decanos y decanas, así como a 11 vicedecanos y vicedecanas en las sedes Calle 100, Campus y la Facultad de Medicina. Los resultados se categorizan así:

- Particularidad de las Facultades. El primer reto que las decanaturas y vicedecanaturas ven para crear una política de investigación se relaciona con las particularidades de la investigación en cada área disciplinar. Por esta razón, piden que la política se piense de tal forma que el hecho de incentivar lineamientos institucionales para la investigación formativa en unas Facultades, no 
dificulte la práctica investigativa en otras. Piden que se haga la política teniendo en cuenta un elemento de transversalidad que sea incluyente en ese aspecto.

- Definición de investigación formativa. Este grupo poblacional afirma que, para lograr lo anterior, es necesario llegar a una definición de investigación formativa que sea, primero, incluyente y consecuente con las particularidades institucionales, y, segundo, que sirva como factor motivacional tanto a estudiantes como a docentes para promover la investigación formativa. El grupo afirma que una forma de facilitar esa definición es aclarar el rol que juega la investigación en la UMNG en cuanto institución de educación superior.

- Transversalidad en el Plan de Estudios. Se debe pensar en la investigación formativa no como aquella que está destinada a espacios específicos en donde es enseñada, sino como el eje transversal de la formación de profesionales. Asegurar su carácter de eje o su transversalidad es asegurar la formación de profesionales integrales. Por el contrario, pensar en la investigación formativa como una forma restringida a espacios definidos, específicos, sin ninguna réplica en otros escenarios, puede ser la causa de las situaciones y los problemas reales que sufren las Facultades actualmente, como son los bajos puntajes en las pruebas Saber Pro, específicamente, en competencias 
relacionadas con la investigación formativa (lecto-escritura, argumentación, etc.).

- Espacios de investigación, formación y motivación. Las decanaturas y vicedecanaturas entrevistadas están de acuerdo, al parecer, en que, actualmente, los espacios de investigación formativa -como los semilleros de investigación o los proyectos de iniciación científica (PIC)-pueden constituir un desgaste profesional para los docentes, pues, teniendo en cuenta que los estudiantes no hallan motivación en la investigación, es difícil garantizar la continuidad de esos procesos y espacios de investigación.

c. Asistentes de investigación

En total, se realizaron dos actividades, en las que participaron 19 asistentes graduados, tanto en el Campus (cinco personas), como en Calle 100 (catorce personas), distribuidos según la Facultad o dependencia a la que pertenecen, como aparece en la tabla 2. 
Tabla 2. Asistentes graduados participantes

\begin{tabular}{l|c|c|c}
\hline \multicolumn{1}{c|}{ Dependencia } & Cantidad & Sede & Egresado \\
\hline Ing. en Mecatrónica & 4 & \multirow{4}{*}{ Calle 100 } & 3 \\
\cline { 1 - 2 } Ing. Civil & 5 & & 5 \\
\hline Ing. en Telecomunicaciones & 2 & & 1 \\
\cline { 1 - 2 } Derecho & 1 & & 0 \\
\cline { 1 - 2 } F. de Educación y Humanidades & 1 & & 1 \\
\hline Admón. de Empresas & 1 & & 0 \\
\hline Medicina & 1 & \multirow{2}{*}{ F. de Medicina } & 0 \\
\hline F. de Ciencias Básicas (Biología) & 1 & & 1 \\
\hline Faedis & 1 & \multirow{2}{*}{ Campus } & 0 \\
\hline Ing. Biomédica & 2 & & 0 \\
\hline
\end{tabular}

Los resultados fueron categorizados así:

- Competencias y habilidades de la investigación formativa. Los asistentes graduados observan que tanto ellos, cuando en su tiempo ingresaron a los semilleros, como los estudiantes que ahora están siendo aceptados en algunos semilleros, tienen carencias en las mismas competencias relacionadas con la investigación formativa. Identifican esto porque son exactamente las mismas competencias y habilidades que tuvieron que fortalecer con esfuerzo adicional para poder permanecer en dichos semilleros. Lo anterior es una lectura de la situación, según la cual existe un fenómeno generalizado que se está repitiendo en la 
formación de los estudiantes y que está evidenciando la carencia de esas competencias.

- Nociones de investigación vs. semilleros. Los asistentes graduados afirman que los estudiantes, como ellos mismos antes de ingresar a un semillero, tienen nociones "desvirtuadas" de lo que son la investigación y los semilleros. Pero, para ellos, la solución depende no solo de aclararles esas nociones a los estudiantes, sino de que la UMNG defina el papel que tiene la investigación. Así, los asistentes consideran que el desarrollo de competencias relacionadas con la investigación formativa no puede quedar exclusivamente restringido a los semilleros, sino que puede practicarse en el aula de clases, independientemente de si los estudiantes participan o no en otros espacios de investigación.

- Difusión de espacios de investigación. Los asistentes graduados reconocen como un obstáculo para la investigación formativa la falta de estandarización de los canales a través de los cuales se difundan las oportunidades de hacer investigación en la UMNG. Argumentan que, además de fomentar la investigación formativa en el aula, es necesario promover, difundir y fortalecer otros espacios de investigación, como son los semilleros, grupos de investigación, congresos, ferias de exposición de proyectos, etc. 
- Asistentes graduados como replicadores de la investigación formativa. Este grupo poblacional, luego de la discusión, concluyó que ellos mismos pueden ser considerados como un posible puente entre los estudiantes y el ejercicio de la investigación formativa. Esto se lograría gracias a la cercanía que tienen con los estudiantes y a que han estado inmersos en el desarrollo de trabajos de investigación.

d. Docentes, directores de programa y directores de centros de investigación

En total, participaron 67 docentes y directores de programa, distribuidos por Facultad, programa y cargo, según lo muestran las tablas 3 y 4. 
Tabla 3. Número de participantes según programa y Facultad

\begin{tabular}{|c|c|c|}
\hline Facultad & Programa & $\begin{array}{l}\text { Número de } \\
\text { participantes }\end{array}$ \\
\hline \multirow{2}{*}{ Faries } & ASSO & 1 \\
\hline & RRII & 1 \\
\hline Facehu & $\begin{array}{l}\text { Educación y } \\
\text { Humanidades }\end{array}$ & 23 \\
\hline \multirow{3}{*}{ F. de C. Económicas } & Admón. de Empresas & 1 \\
\hline & Economía & 2 \\
\hline & Contaduría Pública & 0 \\
\hline F. de Derecho & Derecho & 3 \\
\hline \multirow{7}{*}{ F. de Ingeniería } & Ing. Civil & 9 \\
\hline & Ing. Ambiental & 1 \\
\hline & Ing. Biomédica & 1 \\
\hline & Ing. Industrial & 3 \\
\hline & Ing. en Multimedia & 4 \\
\hline & Ing. en Mecatrónica & 1 \\
\hline & $\begin{array}{l}\text { Ing. en } \\
\text { Telecomunicaciones }\end{array}$ & 0 \\
\hline F. de Ciencias Básicas & Biología & 3 \\
\hline $\begin{array}{l}\text { F. de Medicina y C. de } \\
\text { la Salud }\end{array}$ & Medicina & 4 \\
\hline \multirow{3}{*}{ Faedis } & Admón. de Empresas & 4 \\
\hline & Contaduría Pública & 2 \\
\hline & RIEP & 4 \\
\hline \multicolumn{2}{|l|}{ Total } & 67 \\
\hline
\end{tabular}


Tabla 4. Número de participantes según Facultad y cargo

\begin{tabular}{l|c|c|c}
\hline \multicolumn{1}{c|}{ Programa } & Docente & $\begin{array}{c}\text { Dir. de } \\
\text { programa }\end{array}$ & $\begin{array}{c}\text { Dir. de Centro } \\
\text { de Inv. }\end{array}$ \\
\hline ASso & & 1 & \\
\hline RRII & & & 1 \\
\hline Educación y Humanidades & 23 & & \\
\hline Admón. de Empresas & 1 & & \\
\hline Economía & 1 & 1 & \\
\hline Contaduría Pública & & & \\
\hline Derecho & 1 & & 2 \\
\hline Ing. Civil & 7 & & \\
\hline Ing. Ambiental & & 1 & \\
\hline Ing. Biomédica & & 1 & \\
\hline Ing. Industrial & 2 & & \\
\hline Ing. en Multimedia & 3 & 1 & \\
\hline Ing. en Mecatrónica & & 1 & \\
\hline Ing. en Telecomunicaciones & & & \\
\hline Biología & 1 & 1 & \\
\hline Medicina & 3 & & 1 \\
\hline Admón. de Empresas & 4 & & \\
\hline Contaduría Pública & 2 & & \\
\hline RIEP & 3 & & \\
\hline
\end{tabular}

Los resultados se categorizaron de acuerdo con lo siguiente:

- Incentivos a la investigación. En general, los docentes opinan que una educación basada en proyectos podría brindar las oportunidades para incentivar la 
investigación formativa en la UMNG. La figura 3 también muestra que los docentes creen, inicialmente, en la necesidad de instaurar más asignaturas de Metodología de la Investigación; sin embargo, al discutirlo grupalmente, concluyen que esto no necesariamente solucionaría el problema que tienen en cuanto a la falencia de competencias entre sus estudiantes relacionadas con la investigación formativa. Concluyen que el desarrollo de esas competencias puede darse durante las asignaturas del Plan de Estudios.

- Competencias de la investigación formativa. Según los docentes de humanidades, la lecto-escritura es la competencia que más se fomenta en la asignatura denominada Metodología de la Investigación. Aun así, algunos docentes de los demás programas observan que es precisamente esa la competencia que menos ven desarrollada en los estudiantes. Si bien esto, en principio, puede llevar a afirmar precipitadamente que la clase de Metodología de la Investigación está fallando, tal situación, entre otras (ver figuras 4 y 5), indica realmente que durante el Plan de Estudios los estudiantes pierden la oportunidad de ejercitar y desarrollar las competencias infundadas en Metodología de la Investigación. 


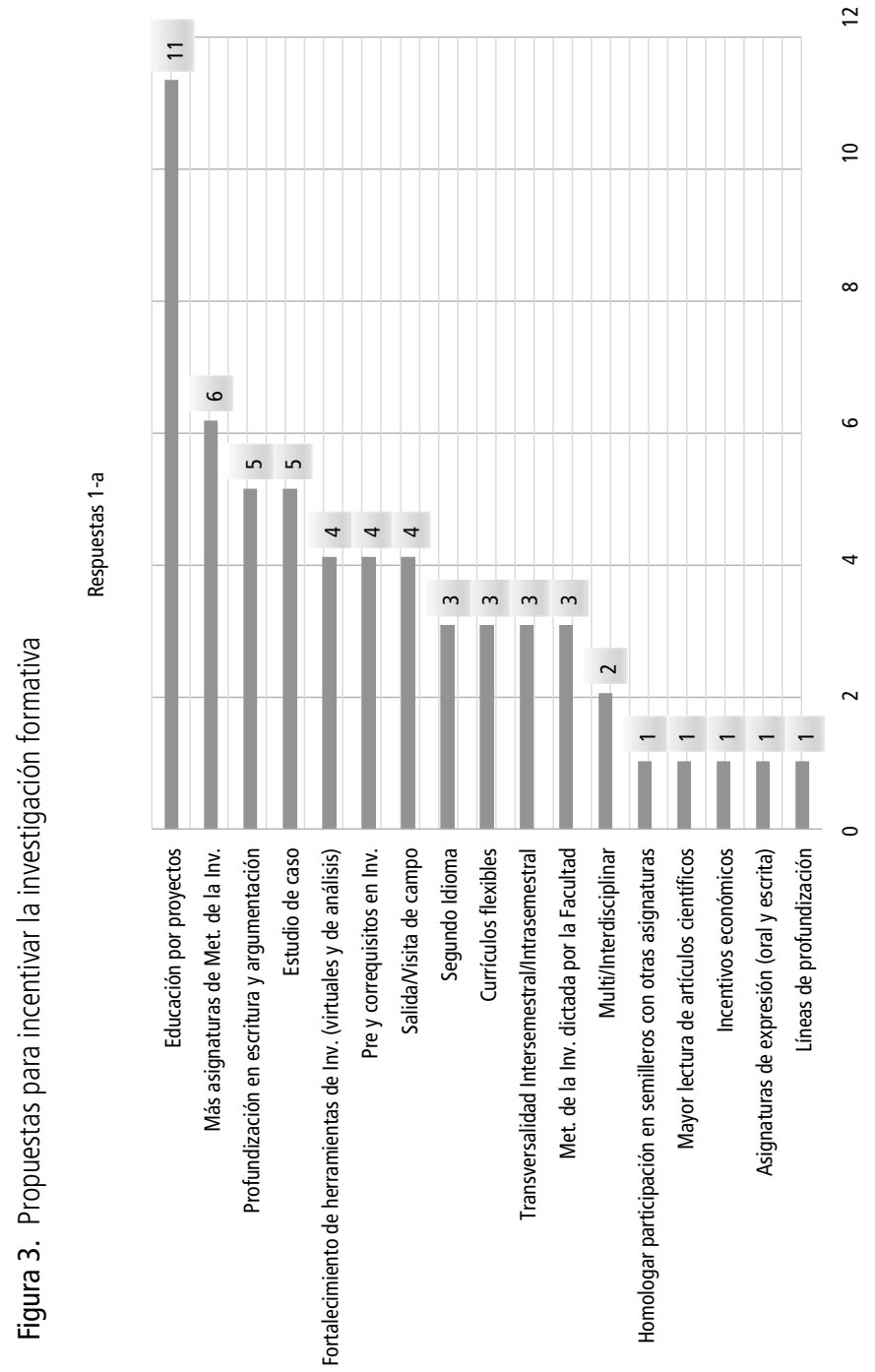




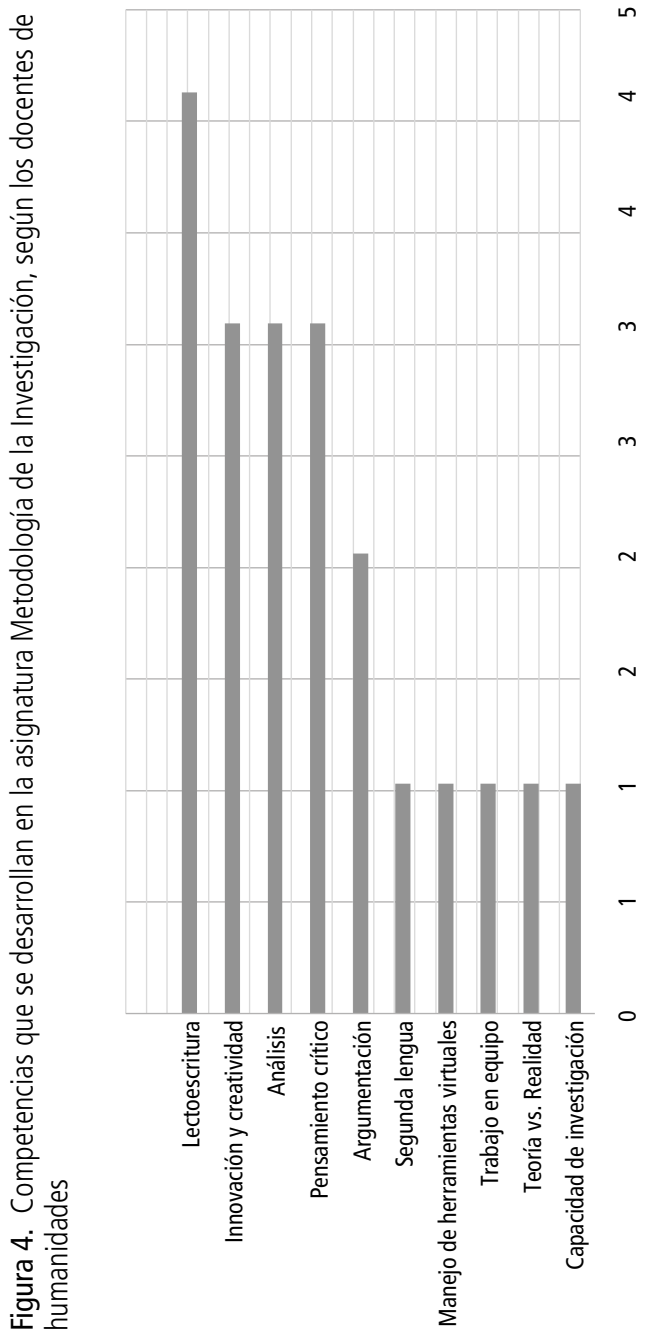




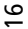

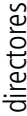

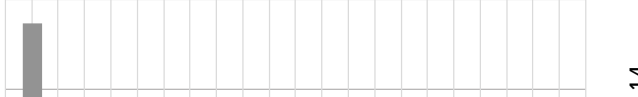

$\stackrel{+}{\Xi}$

$\simeq$

离

气

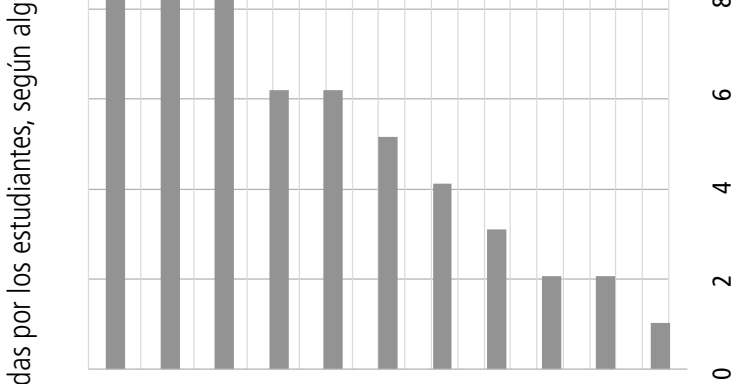

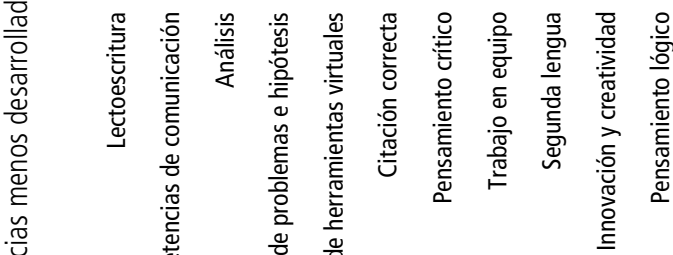

它

เก

끌 
- Herramientas para la investigación formativa. Los docentes y directores de programas y de centros, así como los docentes de humanidades, están de acuerdo en que, además de fomentarse la investigación formativa en las aulas a través de la educación en el marco de proyectos, deben promulgarse espacios adicionales para realizar actividades relacionadas con la investigación formativa, particularmente, espacios de discusión entre docentes, docentes y estudiantes, y estudiantes específicamente, fomentando, preferiblemente, el trabajo interdisciplinario (ver figuras 6 y 7 ).

- Transversalidad, investigación formativa y participación de los estudiantes. Los docentes y directores de programas y de centros de investigación opinan que una política de investigación de la UMNG debe apelar, sobre todo, a la transversalidad, que busque incentivar la investigación formativa en docentes y estudiantes, como un esfuerzo conjunto. 
$\simeq$

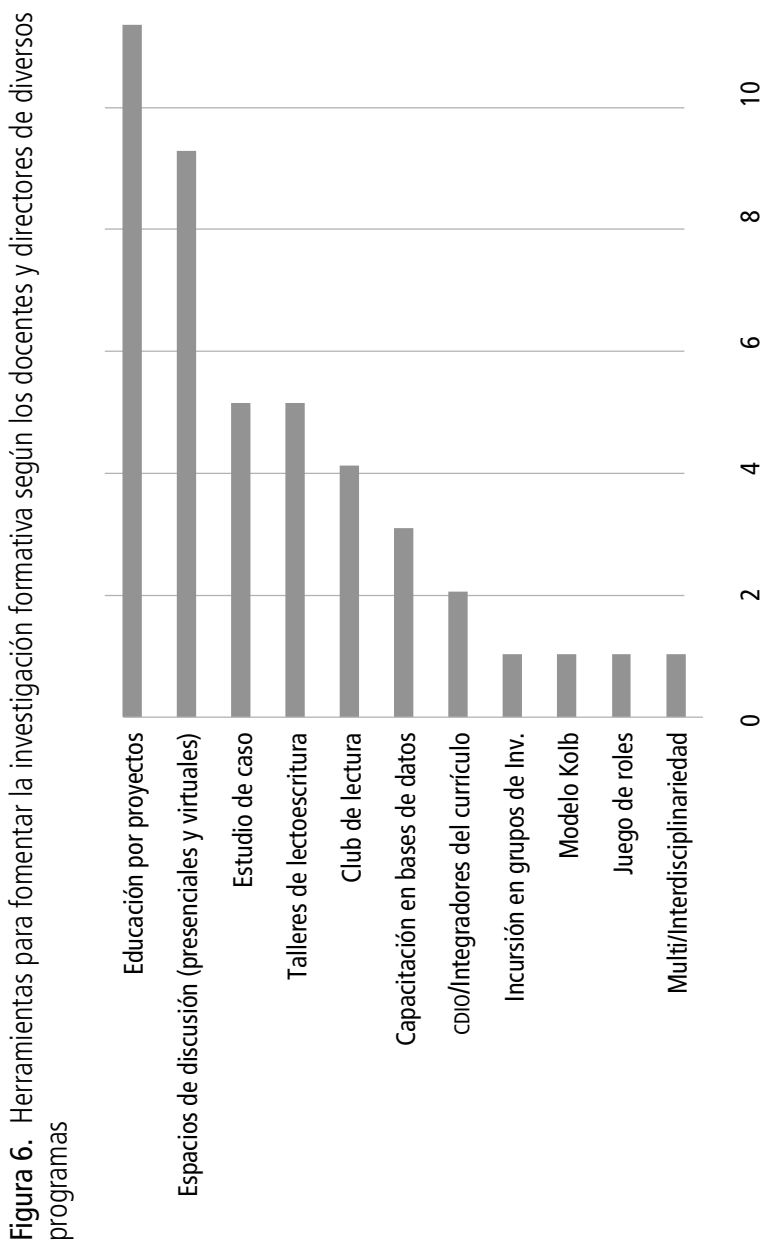




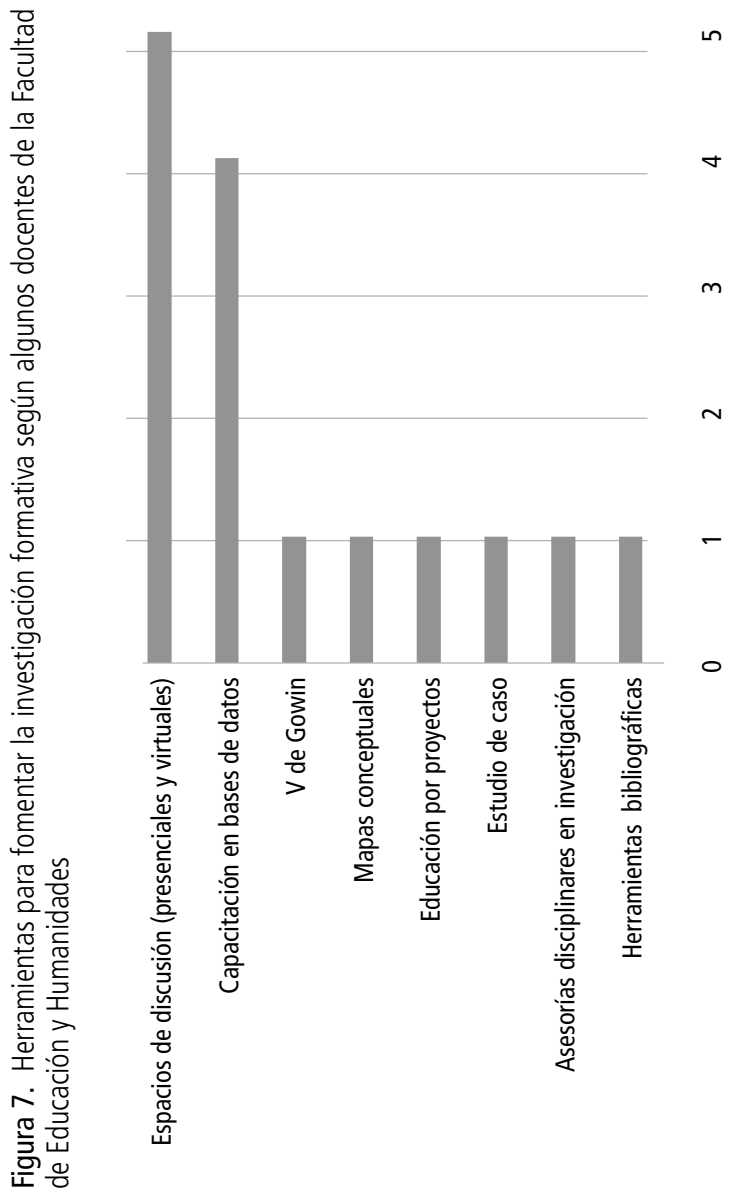




\subsection{Recomendaciones desde el diagnóstico: necesidades frente a la investigación formativa}

Como recomendaciones para la construcción de una política de formación para la investigación, la innovación y el emprendimiento en la UMNG, se enumeraron ciertas necesidades, según si se consideran urgentes o importantes. Las necesidades importantes son aquellas que se deben atender para fortalecer la formación para la investigación, la innovación y el emprendimiento. Por su parte, las necesidades urgentes son necesidades importantes y deben ser atendidas con prelación a las demás.

- Necesidades urgentes:

- Definir el concepto de investigación formativa y su papel en la UMNG.

- Fortalecer entre los estudiantes las competencias relacionadas con la investigación formativa.

- Asegurar la transversalidad de la investigación formativa en el Plan de Estudios.

- Combatir las nociones desvirtuadas de la investigación formativa.

- Asegurar el fomento de la investigación formativa, respetando las particularidades de cada Facultad, como punto de partida. Reconocer y poner en diálogo esas particularidades. 
- Necesidades importantes:

- Visibilizar y promover los semilleros de investigación.

- Construir espacios para la investigación formativa, y darles continuidad.

- Asegurar y promover las relaciones interdisciplinares y multidisciplinares.

- Crear espacios de convergencia en la asignatura Metodología de Investigación, de tal manera que se complementen los conocimientos del área disciplinar y la metodología impartida.

- Reevaluar la financiación de los espacios de investigación (semilleros, grupos de investigación, congresos, encuentros, trabajo de campo, etc.), con el fin de fortalecerlos.

Una vez son catalogadas las necesidades, se distribuyen en una línea de tiempo para su resolución.

\subsection{Proyección de la política FIIE}

La presente política es un planteamiento que, como punto de partida, busca el cumplimiento de una serie de objetivos que conducen a la consolidación y al fortalecimiento de la cultura de la investigación en la UMNG. Por cultura de la investigación, según se verá más adelante, se entiende la forma como la Universidad interioriza y 
refleja la práctica investigativa, a partir de una disposición clara y unos esfuerzos definidos.

Así, el resultado de este primer ejercicio permitió, a la Vicerrectoría de Investigaciones, con el apoyo de docentes de la UMNG, formular una política de formación para la investigación, la innovación y el emprendimiento.

Figura 8. Esquema de la política FIIE

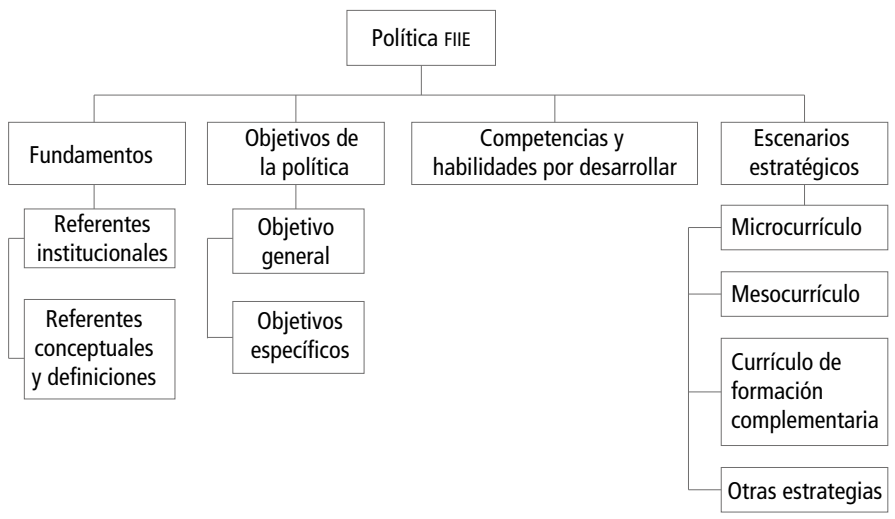





\section{Fundamentos}

En esta sección, se encuentran todos los documentos y definiciones analizados que se articulan con esta política y que surgieron de los ejercicios realizados con los grupos de interés y del grupo asesor de la UMNG. En primer lugar, se encuentran los documentos institucionales y normativos que dan sentido a la construcción de esta política, al tiempo que la articulan con los demás esfuerzos que realiza constantemente la UMNG, desde diversos frentes, para constituirse y mantenerse como una institución educativa de alta calidad. En segundo lugar, se revisan algunos referentes teóricos y académicos que guían conceptualmente la discusión y construcción de esta política, en la medida 
en que aportan las definiciones que le dan sentido y dirección (ver figura 9).

Figura 9. Fundamentos de la política FIIE

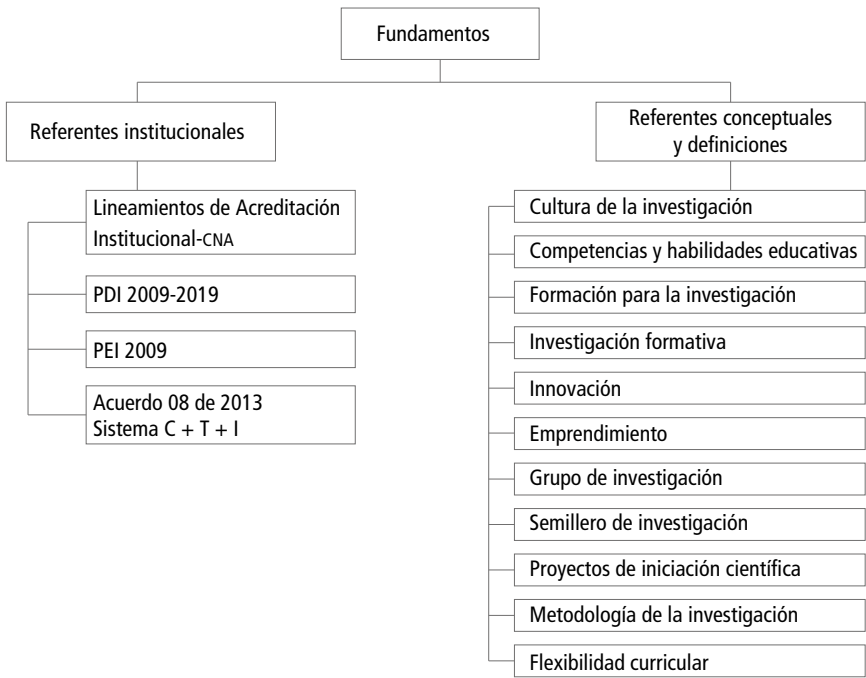

\subsection{Referentes normativos e institucionales}

\subsubsection{Consejo Nacional de Acreditación (CNA): lineamientos de acreditación institucional para programas de pregrado}

Bajo el Factor de Investigación y Creación Artística, se enuncia la característica número 17, concerniente a la formación para la investigación. Allí se señala que las instituciones de educación superior que busquen la acreditación 
deben: "desarrollar políticas y estrategias relacionadas con el reconocimiento de la importancia de introducir a los estudiantes en las dinámicas de generación y apropiación de conocimiento, aplicables de manera diferenciada en los diversos niveles educativos" (CNA, 2014).

Entre los aspectos por evaluar de esta característica, el CNA plantea los siguientes elementos, que permiten orientar políticas, estrategias o planes para fomentar la formación para la investigación:

a. Políticas y estrategias institucionales para favorecer la formación investigativa de los estudiantes, concordantes con los diferentes niveles de formación en el pregrado y el posgrado.

b. Compromiso del profesorado y de los estudiantes en la construcción y sistematización del saber, como forma de actualización permanente.

c. Estrategias y apoyos institucionales que faciliten la construcción y sistematización de conocimientos a los profesores y estudiantes.

d. Existencia de elementos de flexibilización curricular que permitan el ejercicio de procesos de investigación por parte de profesores y estudiantes.

e. Facilidades para la participación de los estudiantes en actividades académicas relacionadas con la investigación científica y/o la creación artística y cultural. 
f. Evaluación y acciones de mejora relacionadas con las políticas y estrategias de enseñanza y aprendizaje en el marco de la formación para la investigación. (CNA, 2014)

Así, para poder seguir cumpliendo como institución universitaria acreditada en alta calidad, la presente política debe contribuir al cumplimiento de los aspectos señalados en la característica número 17, específicamente, construyendo las estrategias que ayuden a consolidar la formación para la investigación desde diversos espacios. Dar cumplimiento a esta característica hace parte de los esfuerzos de la UMNG por fortalecer sus procesos de acreditación institucional.

\subsubsection{Consejo Nacional de Acreditación (CNA):} lineamientos de acreditación institucional para programas de maestría y doctorado

En lo referente a los lineamientos de acreditación institucional para programas de maestría y doctorado, se establece el factor 5 de "Investigación, generación de conocimiento y producción artística”. Según el CNA, la investigación debe estar en el centro de los programas de maestría y doctorado; el CNA también afirma que estos programas deben estar constituidos, tanto en sus objetivos como en su asignación presupuestal, pensando en la 
investigación como uno de sus componentes académicos centrales (CNA, 2010).

Para poder evaluar la calidad de la investigación en el diseño de los programas de maestría y doctorado, el CNA ha señalado las siguientes características indispensables:

- Articulación de la investigación al programa.

- Los grupos, líneas y proyectos de investigación.

- Productos de la investigación y su impacto. (CNA, 2010)

Prestando especial atención a la característica número 1 de este factor, es decir, la articulación de la investigación al programa, la presente política es la herramienta para poder asegurar una mayor vinculación de la formación académica de alta calidad en los programas de maestría y doctorado, con la formación para la investigación, la innovación y el emprendimiento.

\subsubsection{Consejo Nacional de Acreditación (CNA):}

lineamientos de acreditación institucional para programas de posgrado en especialidades médicas

El CNA presenta los lineamientos para especialidades médicas y quirúrgicas, en donde la investigación es resaltada, de nuevo, como uno de los pilares del diseño de los programas, con miras a asegurar su alta calidad. Así, los grupos y líneas de investigación de los programas, el apoyo 
a la producción científica y académica, el fortalecimiento del desarrollo tecnológico, la investigación aplicada y la innovación son de gran importancia (CESU, 2016).

Como elementos de evaluación que permiten acreditar la alta calidad de los programas de posgrado en especialidades médicas, el CNA define las siguientes características:

- Articulación de la investigación al programa: se debe reconocer y promover la investigación aplicada, teniendo en cuenta los convenios y los principios nacionales e internacionales en bioética y experimentación.

- Desarrollo tecnológico e innovación en los programas de especialidad médica: el desarrollo tecnológico y la innovación se entienden, desde los programas de especialidades médicas, como la fuente de nuevas tecnologías, procedimientos, dispositivos, sistemas y demás que permitan mejorar la prestación de un servicio o producto (CESU, 2016).

- Productos académicos y de investigación: se debe evaluar la producción académica y de investigación de los programas de especialidades médicas, basándose en dos aristas: desarrollo tecnológico, nuevas tecnologías, innovación y producción en términos de publicaciones como producto de la investigación (CESU, 2016).

La consideración de los programas de especialidades médicas desde los lineamientos del CNA hace parte del 
fortalecimiento de la formación para la investigación, la innovación y el emprendimiento, para así articular este esfuerzo con el cumplimiento de las características para la acreditación en alta calidad.

\subsubsection{Plan de Desarrollo Institucional (PDI) 2009-2019}

Dentro de su núcleo institucional, la UMNG se define como

[...] un ente universitario autónomo del orden nacional, con régimen orgánico especial, cuyo objeto principal es la educación superior y la investigación, dirigidas a elevar la preparación académica de los miembros de las Fuerzas Militares y de la Policía Nacional, en actividad o en retiro; los empleados civiles del Sector Defensa, los familiares de todos los anteriores, y los particulares que se vinculen a la UMNG. (2013b)

Así, la investigación como concepto general tiene dos aspectos en la UMNG: uno está ligado a la producción de conocimiento desde un punto de vista científico y con un interés de intercambio y de valor de uso para el Estado y el sector productivo (conforme al triángulo de universidad-empresa-Estado); otro está relacionado con la formación académica con excelencia, es decir, consiste en un ejercicio de la enseñanza a través del aprendizaje y la 
construcción del conocimiento. En este segundo aspecto se abre el espacio para la construcción de la política FIIE. Según el objetivo estratégico número 4 del PDI (“Afianzar el sistema de ciencia, tecnología e innovación científica y académica"), se menciona lo siguiente:

Frente a la integración de la investigación al desarrollo académico de programas académicos de pregrado y posgrado se efectuó la identificación de los grupos soporte al desarrollo de líneas de investigación en los programas de posgrado; la identificación de los espacios y procesos pedagógicos de integración entre la investigación y los programas de pregrado; la viabilización del programa de Jóvenes Investigadores, y la elaboración de una matriz de acople entre las temáticas de investigación activas en los grupos y los diferentes programas de pregrado y posgrado. (UMNG, 2013b)

La presente política se construye como herramienta que asegura las vías de acción a lo establecido en el objetivo estratégico mencionado del PDI, específicamente, a la identificación de los espacios en el nivel de formación de pregrado para articular la investigación con los programas y los procesos de formación de los estudiantes.

En el objetivo específico número 4.1.1, se pueden sentar las bases para darle un enfoque curricular y de formación 
complementaria a la presente política, específicamente en los siguientes puntos:

- Integrar la investigación al desarrollo académico de programas académicos de pregrado y posgrado.

- Visibilizar los espacios y procesos pedagógicos de integración de la investigación con los programas de pregrado.

- Identificar los grupos que puedan servir de soporte al desarrollo de líneas de investigación en los programas de posgrado (maestrías de investigación y doctorados).

- Viabilizar los semilleros de investigación y Jóvenes Investigadores. (UMNG, 2013b)

El fortalecimiento de la investigación como parte articulada en los procesos de formación sirve al doble propósito de complementar los procesos de renovación de la acreditación institucional y asegurar el cumplimiento de las directrices internas establecidas en el PDI. Las líneas de acción que se definen más adelante en esta política responden a las necesidades y objetivos identificados dentro del PDI, y además hacen parte del proceso de reacreditación institucional.

\subsubsection{Proyecto Educativo Institucional (PEI) 2009}

Como parte de los fundamentos del PEI de la UMNG, se establece el objetivo siguiente: "Implantar sistemas integrados 
de información, desde el punto de vista de la gestión del conocimiento, como una estrategia que permita visualizar las comunidades del saber y que responda a las necesidades en materia de investigación, desarrollo e innovación de saberes" (UMNG, 2009a).

Así mismo, entre las funciones sustantivas de la UMNG que se definen en el PEI, la investigación adquiere prioridad, pues se destaca: "es necesario poner en marcha acciones que permitan reconocer las implicaciones de esta pluralidad en el aprendizaje de los estudiantes, en el progreso de los profesionales académicos y en el análisis de la relación con el medio externo entre las partes y el todo"; así mismo, se explica: "la investigación debe ser el eje articulador de la docencia y de lo que hoy se denomina la tercera función ( $\mathrm{I}+\mathrm{D}+\mathrm{I}$ = investigación + desarrollo + innovación)" (UMNG, 2009a). De esta forma, se fortalece la necesidad de que la presente política implique un ejercicio directo con la docencia, en donde enseñanza, aprendizaje e investigación se articulen efectivamente. Así mismo, se asegura el cumplimiento de los aspectos por evaluar de la característica número 17, enunciados en los lineamientos de acreditación institucional referidos anteriormente, en los cuales se hace referencia a la necesidad de dar pie a acciones y estrategias que fortalezcan la formación para la investigación, concentradas tanto en los profesores como en los estudiantes. 
3.1.6 Estatuto de ciencia, tecnología e innovación de la UMNG (Acuerdo 08 de 2013)

El Acuerdo 08 de 2013 (UMNG, 2013a) reviste toda la estructura legal, organizacional y operativa que gira alrededor del Sistema de Ciencia, Tecnología e Innovación $(\mathrm{SC}+\mathrm{T}+\mathrm{I})$. Aquí, se le delega a la Vicerrectoría de Investigaciones la función de velar por el fomento de cultura de la investigación, la innovación y el emprendimiento en la UMNG.

En el artículo 17 del Acuerdo se establecen los programas que se deben desarrollar en la UMNG para fomentar y fortalecer la formación para la investigación y la investigación formativa. Jóvenes Investigadores y Asistentes Graduados es el primer programa, que se pone en marcha a partir de la contratación de egresados (de la UMNG o de otras instituciones de educación superior) para participar en actividades investigativas de los grupos de investigación que se hallan en la Universidad.

En el numeral 2 del artículo 17, se menciona que la UMNG debe financiar y promover programas que fomenten la investigación formativa y la investigación científica. Del mismo modo, en el numeral 3 del citado artículo se establece la promoción de publicaciones y divulgaciones de carácter científico de la UMNG, así como se expone el compromiso de estimular y financiar la participación de 
estudiantes y profesores en eventos de carácter científico que sean de interés de la Universidad y estén avalados o inscritos en la Vicerrectoría de Investigaciones. En el marco de la presente política, se definen acciones que apoyen el cumplimiento de esta normativa, concentrando esfuerzos en el fortalecimiento de la participación de la comunidad neogranadina en eventos de divulgación de carácter académico e investigativo.

Por último, en el mismo Acuerdo, se establece que la UMNG se encargará de apoyar financieramente las iniciativas que fomenten la cultura investigativa, innovadora y emprendedora en la Universidad, y ayuden a dar cumplimiento con lo que se dictamina en el Acuerdo.

La presente política, considerada como una iniciativa que busca beneficiar la cultura investigativa en la UMNG, plantea las acciones que deben desarrollarse como parte del fomento de la investigación y de su articulación con la formación. La UMNG, al asumir el reto de la construcción de esta política, garantiza el esfuerzo financiero y operativo que implica la ejecución de las líneas de acción propuestas, entendiéndolo como un ejercicio integral de fortalecimiento institucional, como una medida para asegurar la calidad y como una acción en pro del proceso de reacreditación institucional. 
3.1.7 Sistema de Ciencia, Tecnología e Innovación

El SC + T + I de la UMNG define sus dinámicas de investigación y financiación de proyectos de investigación para los distintos grupos de investigación presentes en la Universidad. Al describir su dinámica de investigación, se define lo siguiente: "La principal unidad de base para el desarrollo de los procesos de investigación es el proyecto de investigación, desarrollo tecnológico o de innovación" (UMNG, 2009b). De allí, se destaca la posibilidad de utilizar una metodología basada o inspirada en proyectos para desarrollar procesos de investigación, esta vez enfocadas en la formación para la investigación y la investigación formativa.

\subsection{Referentes teóricos y conceptuales}

Como soporte de la política FIIE, se ha hecho un recorrido teórico que permite establecer los límites referenciales con base en los cuales se discuten las definiciones y los principios que componen esta política. Al mismo tiempo, se plantea esta reconstrucción de referentes teóricos como la justificación y la influencia para proponer las líneas estratégicas de la política.

Esta discusión teórica versa sobre la definición de la formación tanto para la investigación como para la investigación formativa, con el propósito de establecer en qué 
radican sus diferencias y cómo se integran aquellas al proceso de formación de profesionales integrales. También, se discute acerca de la formación para la innovación y el emprendimiento, señalando su relación con la formación superior de calidad. Así mismo, se presentan los recursos y estrategias más adecuados, según la discusión académica, para fomentar y fortalecer la formación para la investigación y la investigación formativa en contextos de educación superior de alta calidad.

\subsubsection{Definiciones}

Como parte fundamental de la política FIIE, se han escogido algunas definiciones. Estas permiten determinar conceptualmente varios de los temas que se discuten y se abordan en esta política. La construcción de tales definiciones partió de un doble ejercicio: la búsqueda bibliográfica y las actividades de discusión sobre los conceptos y sus definiciones. La razón de la utilización de las definiciones es, principalmente, dar claridad a los elementos que son objeto de acción en el marco de esta política, para así fijar límites claros de los alcances de estas acciones. Los conceptos y sus definiciones son los siguientes:

- Cultura de la investigación, la innovación y el emprendimiento. Conjunto de prácticas, acciones, significados, disposiciones y directrices que se interiorizan, 
se reproducen y se manifiestan de forma colectiva, y que determinan el comportamiento institucional hacia la investigación, tanto en su desarrollo para la producción y la generación de conocimiento a nivel científico y académico, como en la formación para la investigación con miras a promover la innovación y el emprendimiento.

- Competencias educativas. Conjunto de habilidades enfocadas a la resolución de problemas y retos de naturaleza compleja, que necesitan el uso y desarrollo de más de una habilidad. Según lo concibe el PEI de la UMNG: La competencia se define como una superación de lo teórico y lo pragmático, es decir, se concibe más allá de lo académico y lo operacional, entendiéndola como la "capacidad de regulación básica que desarrolla cada persona para adaptar y modificar todo aquello que tiene que ver con su propio aprendizaje y que le permite tomar decisiones y posturas frente a su realidad como ser humano". (UMNG, 2009, p. 50)

- Habilidades. Facilidad, agilidad y experticia para realizar una o varias acciones enfocadas en lograr un resultado concreto, que se produce gracias al esfuerzo y a la práctica (ver Sturgess, 2012).

- Formación para la investigación. Miyahira Arakaki escribe: 
[...] conjunto de acciones orientadas a favorecer la apropiación y desarrollo de los conocimientos, habilidades y actitudes necesarios para que estudiantes y profesores puedan desempeñar con éxito actividades productivas asociadas a la investigación científica, el desarrollo tecnológico y la innovación, ya sea en el sector académico o en el productivo. (2009)

Esta formación se da de manera transversal a todo el proceso de formación profesional, e implica esfuerzos, estrategias y actividades tanto curriculares como extracurriculares.

- Investigación formativa. Tipo de investigación cuya finalidad es la apropiación del conocimiento existente a través del ejercicio de actividades investigativas entre el profesor y el estudiante (ver Miyahira, 2009). En este sentido, es una herramienta del proceso de enseñanza-aprendizaje.

La investigación formativa no se orienta a la generación de conocimiento (ver Parra, 2004), sino al descubrimiento, desarrollo y fortalecimiento de competencias y habilidades sustanciales para la formación de profesionales integrales.

- Innovación. Resultado de un proceso guiado por la creatividad, apalancado usualmente por el nuevo conocimiento. La innovación está dirigida a la búsqueda 
y descubrimiento de nuevas oportunidades y a la implementación de modelos para aprovecharlas, gracias a lo cual se crea valor y se genera un impacto en lo social, lo económico y lo ambiental.

- Emprendimiento. Acción de tomar una iniciativa de cambio, desde una perspectiva de liderazgo hacia el logro de objetivos definidos, asumiendo y gestionando los riesgos por medio de la práctica sistemática de la innovación. El emprendimiento construye, por definición, valor.

- Grupo de investigación. Según Colciencias:

Se define grupo de investigación científica o tecnológica como el conjunto de personas que se reúnen para realizar investigación en una temática dada, formulan uno o varios problemas de su interés, trazan un plan estratégico de largo o mediano plazo para trabajar en él y producir unos resultados de conocimiento sobre el tema en cuestión. Un grupo existe siempre y cuando demuestre producción de resultados tangibles y verificables, fruto de proyectos y otras actividades de investigación convenientemente expresadas en un plan de acción (proyectos) debidamente formalizado. (2015)

Los grupos de investigación se presentan también como espacios de oportunidad al trabajo interdisciplinar y multidisciplinar. 
- Semillero de investigación. Estrategia de enseñanza y aprendizaje, cuyo objetivo es el desarrollo de la formación para la investigación, en el cual interactúan diversos actores (profesores, asistentes graduados y estudiantes), para favorecer el aprendizaje colaborativo, orientado, cooperativo y autónomo, así como la formulación de preguntas de investigación, el planteamiento de soluciones a problemas del entorno, el desarrollo de competencias y habilidades comunicativas, y la aptitud de trabajar en grupo, inclusive, en equipos interdisciplinares y multidisciplinares.

- Proyectos de iniciación científica (PIC). Proyectos que se ejecutan durante un periodo de seis (6) meses por estudiantes de pregrado, bajo la tutoría de un profesor de la Universidad, con el fin de fomentar la investigación formativa entre diferentes Facultades. Estos proyectos deben contribuir al fortalecimiento de las líneas de investigación y de los grupos de investigación de la Facultad que los propone (ver UMNG, 2013).

- Metodología de la investigación. Disciplina del conocimiento a partir de la cual se desarrollan, se estudian, se construyen y se apropian las herramientas, los saberes y la rigurosidad científica necesaria para ejecutar actividades relacionadas con la investigación, la producción de conocimiento y la enseñanza-aprendizaje 
(ver Instituto Nacional de Estadística, Geografía e Informática, 2005).

- Flexibilidad curricular. Según el Ministerio de Educación Nacional (2007):

Un currículo flexible es aquel que mantiene los mismos objetivos generales para todos los estudiantes, pero da diferentes oportunidades de acceder a ellos: es decir, organiza su enseñanza desde la diversidad social, cultural de estilos de aprendizaje de sus alumnos, tratando de dar a todos la oportunidad de aprender.

El currículo flexible debe estar enfocado en el desarrollo de habilidades necesarias para la formación de profesionales integrales, así como de una cooperación académica basada en un modelo multidisciplinar e interdisciplinar (Rodríguez Durán, 2015).

\subsubsection{La importancia de la formación para la} investigación, la innovación y el emprendimiento

La relación interdependiente que se asume en la UMNG de la educación superior de alta calidad y la investigación requiere de esfuerzos conjuntos para promover estos dos componentes de forma simultánea, de tal modo que dicha relación constituya el núcleo de la formación de profesionales integrales. Si bien en la UMNG existen múltiples apoyos, estímulos y esfuerzos con el objetivo de ser un 
referente en investigación científica con repercusión en la sociedad y, específicamente, en el triángulo de universidad-empresa-Estado, es necesario redoblar los esfuerzos para fortalecer la relación directa existente entre formación e investigación, concretamente en la formación para la investigación, la innovación y el emprendimiento.

La relación entre educación formal e investigación no siempre resulta evidente, y, en la mayoría de los casos, se da por sentada. Esto se debe principalmente a que existe una visión estática sobre la investigación como un mero ejercicio de producción, pero se olvida el papel que tiene esta en el desarrollo de tareas investigativas, en el descubrimiento y fortalecimiento de talentos y habilidades profesionales, en la construcción de conocimiento y en procesos de enseñanza-aprendizaje en la esfera universitaria. La investigación hace parte de la realidad de la formación, más allá de la producción científica.

Una de las principales ventajas de la relación que se da entre investigación y formación o, mejor, de la investigación en espacios de formación, es la apropiación del proceso de aprendizaje por parte de los estudiantes. A través del desarrollo del ejercicio investigativo, a nivel educativo, se fortalecen la autonomía y ciertas características de un profesional integral, tales como la capacidad creativa y crítica (ver Cruz y Pfeifer, 2007). Esto es un indicio de que la articulación entre investigación y formación va más allá 
de un mero hecho académico, y, en cambio, tiene una relación directa con la formación de profesionales integrales.

La formación para la investigación en la educación formal también cumple el objetivo de nutrir una cultura de la investigación, que se guíe por un pensamiento crítico y autónomo, y que les permita tanto a profesores como a estudiantes acceder a los nuevos desarrollos del conocimiento (ver Restrepo Gómez, 2006). Al ayudar a construir aspectos de tal peso en la educación superior, la formación para la investigación -si se habla de la profesionalización integral- deja de pertenecer al plano de la formación complementaria y se convierte en un elemento fundamental e interconectado en esos procesos de educación y aprendizaje (ver Scott y Vincent-Lancrin, 2014). La formación para la investigación permite que, en el proceso de formación de profesionales integrales, ellos no solo adquieran conocimiento, sino que se apropien de este y afiancen las habilidades necesarias para poder aplicarlo en diferentes contextos.

Así como sucede con la relación entre investigación y formación, de igual forma existe un lazo profundo de correlación entre formación para la innovación y el emprendimiento y la formación de profesionales integrales. En un primer momento, se puede afirmar que la formación para la innovación y el emprendimiento tiene como función explorar y explotar habilidades empresariales en 
los estudiantes en formación; sin embargo, su función está mucho más cercana al descubrimiento y el desarrollo de habilidades que necesita un profesional integral, quien debe tener la capacidad de generar impacto en la sociedad, desempeñándose de manera competitiva en sus entornos laborales desde una perspectiva innovadora y emprendedora (ver Scott y Vincent-Lancrin, 2014). Esto conduce a una reflexión mucho más compleja sobre la formación para la investigación, la innovación y el emprendimiento, que permite superar visiones simplistas de la relación entre investigación y formación. Esas visiones suelen asumir que la formación para la investigación solo tiene como función formar investigadores, cuando realmente se trata del descubrimiento y el ejercicio de habilidades que también alimentan la formación de profesionales integrales.

Estas habilidades, que se busca descubrir y desarrollar a partir de una formación en investigación, innovación y emprendimiento, pueden categorizarse en tres dimensiones: dimensión de la información, dimensión de la comunicación y dimensión ética y del impacto social. Estas dimensiones permiten entender el carácter complejo e integral de la formación que se busca fortalecer con la presente política, y dan unas directrices básicas para la construcción de líneas de acción que permitan la ejecución de la política. 


\subsubsection{Dimensión de la información}

La primera dimensión involucra a los estudiantes con la habilidad de acceder, evaluar y descubrir información. Al mismo tiempo, implica el desarrollo de las habilidades necesarias para modelar y transformar esa información, con el objetivo de generar nuevo conocimiento o de usar el conocimiento existente para construir nuevas ideas (ver Ananiadou y Claro, 2009). El pensamiento crítico, argumentativo y lógico, al igual que la apropiación de conocimiento existente, se convierten en competencias y habilidades cruciales en esta dimensión.

\subsubsection{Dimensión de la comunicación}

Esta dimensión tiene como objetivo permitir que el estudiante en formación afiance las habilidades y reúna las características necesarias para poder hacer parte de una comunidad más extensa, en donde fluya, circule y trabaje el conocimiento. Esto implica construir y desarrollar habilidades y capacidades comunicativas, de tal forma que se tenga la capacidad de comunicarse asertivamente, de manejar con perspectiva crítica y analítica la información, así como de realizar intercambios para la consolidación o generación de nuevo conocimiento (ver Ananiadou y Claro, 2009). Las competencias y habilidades de la comunicación escrita y verbal, entre otras, hacen parte de esta 
dimensión y serán objeto de atención dentro de las líneas de acción de esta política.

\subsubsection{Dimensión ética y del impacto social}

Esta dimensión responde a las necesidades contextuales que se le presentan al profesional de hoy en día, ante fenómenos como la globalización y el multiculturalismo. En esta dimensión, se busca desarrollar un conjunto de habilidades, capacidades y también posturas respecto al impacto que pueden generar las acciones de los individuos en un ámbito social, económico o ambiental. Así, esta dimensión se divide en dos subdimensiones.

La primera corresponde a la responsabilidad social, que se relaciona con la capacidad de reconocer los riesgos que se tienen con ciertos tipos de actividades, y con la habilidad para reconocer criterios de responsabilidad con miras al uso adecuado de ciertos tipos de información o conocimiento.

La segunda se refiere al impacto social, la cual se torna más complicada de medir, ya que se ocupa de la construcción de la conciencia y el reconocimiento del impacto que ciertas actividades investigativas, innovadoras y emprendedoras producen sobre la sociedad, tanto a nivel positivo (para reforzar y promover dicho impacto) como a nivel negativo (para prevenir y mitigar el impacto) (Ananiadou y Claro, 2009). 
Esta dimensión, con su doble componente, fortalece la formación de profesionales integrales con la perspectiva de la correlación del individuo y el entorno, en donde se entiende que un profesional integral debe ser también un agente del impacto positivo en su entorno social, económico y ambiental.

\subsubsection{Formación para la investigación e investigación formativa}

Uno de los primeros retos es poder trazar los límites conceptuales entre la formación para la investigación y la investigación formativa. Si bien estas son realidades educativas que se presentan de forma simultánea en el quehacer cotidiano de las instituciones de educación superior, definitivamente sirven en sentidos relacionados pero distintos y responden a lógicas, fines y estrategias diferenciadas. La primera tarea fundamental -a nivel teórico y conceptual- de la presente política consiste en exponer claramente tanto las diferencias que hay entre esas dos realidades, como su importancia en un contexto de formación profesional.

La formación para la investigación tiene la clara intención de brindarles a los estudiantes una iniciación e inmersión en las lógicas y las prácticas de la investigación científica (ver González Cardona, 2017). De este modo, se 
puede definir la formación para la investigación como un conjunto de conocimientos, prácticas y estrategias enfocado en promulgar el descubrimiento, desarrollo y fortalecimiento de competencias y habilidades necesarias para el desarrollo de actividades y acciones relacionadas con la investigación científica, bien sea con fines productivos o académicos (ver Guerrero Useda, 2007).

Es importante mencionar que esta inducción al pensamiento científico no es única, pues se da de múltiples formas, pues las áreas del conocimiento y sus disciplinas cuentan con consensos respecto a lo que puede definirse como pensamiento científico y como método científico. Independientemente de esto, la formación para la investigación trata precisamente de introducir gradualmente al estudiante en las distintas temáticas, metodologías y herramientas, que permiten alcanzar la formación de profesionales integrales. Los profesionales de este nivel tienen la capacidad, las competencias y las habilidades para desarrollarse en contextos de investigación científica y de innovación tecnológica y académica.

La formación para la investigación constituye un eje transversal de la formación profesional, aunque está limitada a los escenarios más especializados, como las maestrías y los doctorados. Al respecto, se lee:

En sentido estricto, y según lo contempla la legislación educativa colombiana, la formación de investigadores 
está reservada a los programas de maestría y doctorado. Sin embargo, no cabe duda de que una formación investigativa básica, en los niveles de pregrado, contribuye al desarrollo de competencias y habilidades de aprendizaje necesarias para el ejercicio profesional; además, fomenta la formación de una cultura investigativa y abre la posibilidad de encontrar personas talentosas, que deseen orientarse hacia la investigación como actividad profesional, dentro o fuera de la universidad. (Parra Moreno, 2004)

Dado lo anterior, cabe resaltar que la formación para la investigación va más allá de la formación de investigadores, y que, de hecho, su principal función es complementar los procesos de formación de calidad de profesionales integrales. Como tal, el fomento de la formación para la investigación es, entonces, una actividad que asegura la calidad de la educación en una institución de educación superior.

De otro lado, la investigación formativa hace referencia al uso de diversas maneras de hacer investigación (herramientas, metodologías, estrategias, etc.), como medio para el proceso de enseñanza-aprendizaje en la formación de profesionales integrales. Su objetivo principal, como actividad académica, consiste en difundir conocimiento y dar vías de apropiación, enseñanza y aprendizaje del conocimiento a los estudiantes, a través de ejercicios 
prácticos con los cuales se emulan acciones relacionadas con la investigación (ver Miyahira Arakaki, 2009).

En otras palabras, la investigación formativa explora la relación que se puede trazar entre diversos ejercicios investigativos y la formación, a través de la enseñanza y el aprendizaje. En esa relación de investigación y enseñanza-aprendizaje, se entiende que

[...] la denominada investigación formativa en la educación superior es un tema-problema pedagógico. Aborda, en efecto, el problema de la relación docencia-investigación o el papel que puede cumplir la investigación en el aprendizaje de la misma investigación y del conocimiento, problema que nos sitúa en el campo de las estrategias de enseñanza y evoca concretamente la de la docencia investigativa o inductiva o también el denominado aprendizaje por descubrimiento. Por tratarse de un problema pedagógico y didáctico, es menester iniciar su estudio desde las estrategias de enseñanza, ya que su presencia es consustancial, como ya se sugirió, a una de las grandes vertientes o estrategias de enseñanza: la de aprendizaje por descubrimiento y construcción. (Restrepo Gómez, 2003)

De este modo, la investigación formativa, al igual que la formación para la investigación, también tiene como función principal el desarrollo de competencias y habilidades 
que hagan parte del proceso de formación de un profesional integral, con ética y responsabilidad social. La investigación formativa tiene la labor de desarrollar esas competencias y habilidades como parte de un proceso de formación (ver Jiménez, 2006). Como parte del aporte que realiza Restrepo Gómez (2003), se debe resaltar su idea según la cual el enfoque de la investigación formativa en estrategias de aprendizaje por descubrimiento implica también promulgar la curiosidad y la autonomía del estudiante. Con la investigación formativa se da una mayor responsabilidad al estudiante, como agente de su propio proceso de formación. Por esto, es necesario el uso de estrategias específicas para asegurar una formación integral, según se ha enunciado.

\subsubsection{Recursos y estrategias con miras a la formación para la investigación y la investigación formativa}

Los referentes teóricos hacen varias recomendaciones y salvedades respecto al tipo de herramientas, estrategias y recursos que pueden utilizarse para fomentar y poner en práctica la formación para la investigación y la investigación formativa. Una de las recomendaciones más significativas tiene que ver con la forma como esos dos procesos formativos deben funcionar de manera simultánea, durante la formación profesional: 
[...] la formación para la investigación y la investigación formativa se deben desarrollar en interacción continua. $\mathrm{Y}$ es que con la aplicación de las estrategias de investigación formativa se desarrollan en los estudiantes las capacidades de interpretación, análisis y síntesis de la información; y, además, se estimula la formulación de problemas, el pensamiento crítico y otras capacidades como la observación, la descripción y la comparación, todas directamente relacionadas con la formación para la investigación. (Miyahira Arakaki, 2009)

El desarrollo de este tipo de habilidades y capacidades corresponde al objetivo principal de la presente política. Así, mientras a la investigación formativa se le asigna un espacio específico de acción para el desarrollo de esas estrategias de aprendizaje -p. ej., el aula o los semilleros de investigación-, la formación para la investigación, en cambio, se presenta de manera transversal al proceso de formación de los profesionales. Por ende, se busca fortalecer no solo la investigación formativa, sino también la formación para la investigación, para así tener un alcance mayor y transversal en la Universidad.

Entonces, surge una pregunta: ¿en dónde se halla el límite, en el ejercicio práctico, entre la formación para la investigación y la investigación formativa? Esta pregunta es válida, pues ambos procesos utilizan las mismas 
estrategias y herramientas pedagógicas, e, inclusive, hacen parte de los mismos procesos de desarrollo de competencias y habilidades específicas. La diferencia crucial está en los tiempos y los escenarios en los que puede presentarse cada una de estas realidades educativas.

Se entiende que la investigación formativa está contenida en la formación para la investigación. De esta forma, la primera se comprende con el enfoque de aplicación según las asignaturas de los planes de estudio, limitando así su escenario y tiempo de acción. La formación para la investigación, por su parte, es mucho más compleja, pues atraviesa varios escenarios y varía sus tiempos. La formación para la investigación puede comenzar en el aula, desde la asignatura y la investigación formativa, pero también se nutre en escenarios como los semilleros de investigación, las actividades extracurriculares, los proyectos de iniciación científica (PIC), proyectos de emprendimiento, congresos, talleres, entre otros espacios.

De esta forma, las principales estrategias y metodologías de aprendizaje que se pueden aplicar en la investigación formativa comprenden el método de la enseñanzaaprendizaje por proyectos, la enseñanza a través de la escritura de ensayos, el aprendizaje basado en problemas, el diseño de proyectos y anteproyectos de investigación, las dinámicas de los clubes de revista y los seminarios, entre otros (ver Restrepo Gómez, 2003). Este tipo de 
investigación puede asegurarse desde el escenario de un plan de estudios con cursos que potencien y dinamicen procesos de enseñanza-aprendizaje integrales y aplicables en todas las áreas disciplinares.

Ahora, las estrategias y metodologías de aprendizaje apuntan a la construcción y el descubrimiento del conocimiento, pues conducen al estudiante a realizar un esfuerzo mayor para formular preguntas, resolver situaciones problemáticas planteadas por el profesor e ir construyendo su propio camino hacia una solución. Por supuesto, este tipo de estrategias permite fomentar la autonomía de los estudiantes y, al mismo tiempo, responsabilizarlos de su proceso formativo. Aquí, tanto profesores como estudiantes adquieren la misma responsabilidad en cada nivel de formación.

Con esto se busca implementar lógicas y metodologías activas, en las que la práctica y la acción ganen protagonismo en el proceso de la enseñanza y el aprendizaje. Así, el proceso de apropiación, de descubrimiento y de la organización del conocimiento deja de ser un mero ejercicio unidireccional y se convierte en una práctica participativa (ver Miyahira Arakaki, 2009; Restrepo Gómez, 2006), que le da al estudiante un rol más importante y lo invita a desarrollar, dentro del aula, las competencias y habilidades relacionadas con la formación para la investigación, la innovación y el emprendimiento. Algunas de las estrategias 
de aprendizaje, recomendadas para fortalecer dicha formación, se observan en la tabla 5.

Tabla 5. Metodologías de aprendizaje

\section{Estrategias en las asignaturas}

a. Metodología por proyectos

b. Aprendizaje basado en problemas

c. Estudios de caso

d. Seminario alemán

e. Escritura de ensayos

f. Curso denominado Metodología de la Investigación

g. Clubes de revista

Pero la formación para la investigación requiere de la interacción con otros espacios adicionales a la asignatura, que complementen y fortalezcan el proceso de una manera transversal a la formación, como los semilleros de investigación. Estos son espacios para la formación en investigación, que, además, permiten enriquecer el perfil profesional de sus miembros. Por esto, aunque usualmente se conciben como espacios extracurriculares (ver Jaimes Camacho, 2009), son fundamentales para la formación profesional. Es importante, por lo tanto, que como parte de las estrategias relacionadas con la formación para la investigación se considere el trabajo fuera del aula o, incluso, la interdisciplinariedad, con el fin de incentivar la transversalidad curricular en el Plan de Estudios. 
3.2.5 Formación para la innovación y el emprendimiento

La formación para la innovación y el emprendimiento también hace parte del fomento de una cultura investigativa, como componente de una formación integral de profesionales. El proceso de formación de un profesional integral requiere de este la capacidad de generar un impacto a través del desempeño en sus labores. Este impacto, usualmente, va acompañado del reconocimiento de los cambios y las oportunidades que surgen en diversas realidades. Formar para la innovación implica el desarrollo de la habilidad entre los profesionales para llevar a cabo procesos en donde se descubren oportunidades, se modela una idea para aprovechar una oportunidad y se implementa tal idea buscando unos resultados que generen impacto (Scott, 2012). La posibilidad de poder actuar sobre esas oportunidades y esos cambios también supone una disposición a la toma de decisiones, al liderazgo y a la constancia. Por eso, una formación para la innovación y el emprendimiento hace parte fundamental en la educación superior y constituye procesos que se tienen que dar de forma conexa.

La relación entre innovación, creatividad e impacto, y la formación para el emprendimiento es directa con los actos de crear, mantener, liderar y brindar resultados. Esto significa que entre innovación y emprendimiento hay 
una relación muy profunda, de tal forma que el emprendimiento se alimenta de la innovación o se entiende como la práctica constante, dirigida y sistemática de esta (ver Drucker, 2002).

El emprendimiento supone la realización de cambios sobre formas preestablecidas o la actitud para afrontar cambios que surgen de diversas realidades; lo anterior está acompañado de habilidades para ejecutar tareas, ejercer el liderazgo y tomar decisiones de forma asertiva. La formación para el emprendimiento es vital, pues gracias a aquella los profesionales no solo serán muy competentes, sino que también tendrán la capacidad para producir un impacto positivo y cambios en el ámbito social, económico y ambiental (ver Martin Trust Center, 2017).

La presente política se encarga de plantear las líneas de acción a través de las cuales se asegura el fomento de la formación para la innovación y el emprendimiento. 



\section{Objetivos de la política FIIE}

\subsection{Objetivo general}

Fortalecer los procesos de formación para la investigación, la innovación y el emprendimiento en la UMNG, con la idea de promover el desarrollo de las competencias y habilidades necesarias en la formación de profesionales autónomos, reflexivos, críticos, éticos y socialmente responsables, con capacidades para la argumentación, la rigurosidad científica y el trabajo colectivo. 


\subsection{Objetivos específicos}

- Promover la cultura investigativa a través del uso de metodologías y estrategias pedagógicas, orientadas al desarrollo de competencias y habilidades relacionadas con la investigación formativa.

- Potenciar la capacidad investigativa, innovadora y emprendedora de los estudiantes de la UMNG.

- Fomentar entre los profesores de la UMNG la formación para la investigación, la innovación y el emprendimiento, así como la investigación formativa.

- Articular espacios, actividades y estrategias de fomento de la formación para la investigación, la innovación y el emprendimiento con el currículo actual de la UMNG.

- Impulsar la formación de profesionales con la capacidad, la habilidad y la iniciativa de trabajar en equipos multidisciplinares e interdisciplinares.

- Incentivar la población profesoral para que implemente estrategias de aprendizaje por descubrimiento y construcción en la elaboración de sus programas de cursos o syllabus.

- Establecer las estrategias necesarias para alimentar la formación de profesionales con un sentido de la responsabilidad ética, social y ambiental. 


\section{Habilidades, competencias y desempeños por desarrollar con la política FIIE}

Conforme a lo expuesto anteriormente, las competencias y habilidades se conciben como la relación contextual entre la teoría y la práctica, como las habilidades y desempeños que se inscriben en el campo de la disposición más la acción, de las capacidades intelectuales más la habilidad para resolver problemas reales (ver Sánchez y Arias, 2009). Ahora bien, para descubrir y desarrollar las competencias educativas, habilidades y desempeños, es necesario un proceso de construcción y transformación educativa, que se realiza a través del aprendizaje del ser humano, hasta el momento en que se convierte en un profesional integral. 
Por esto, conviene entender las competencias, habilidades y desempeños no como un set de "requisitos" que debe tener un individuo, sino como una parte del crecimiento, la cual se articula consecuentemente con el proceso de educación y enseñanza-aprendizaje en la institución universitaria. El descubrimiento y el desarrollo de estas competencias, habilidades y desempeños también requieren, entonces, de un proceso educativo y de aprendizaje compuesto por varias estrategias y escenarios a través de todo el proceso de formación de los estudiantes como profesionales integrales (Ananiadou y Claro, 2009). La presente política construye, precisamente, las líneas de acción que permiten que se dé ese proceso de formación, de manera transversal, en la UMNG.

Como parte del esfuerzo para fomentar la formación para la investigación, la innovación y el emprendimiento, se han identificado las competencias y habilidades esenciales que esta política busca fortalecer y desarrollar (ver tabla 6). 
Tabla 6. Competencias y habilidades relacionadas con la política FIIE

\begin{tabular}{|c|c|}
\hline \multicolumn{2}{|c|}{ Competencias y habilidades por fortalecer } \\
\hline $\begin{array}{l}\text { a. Competencias } \\
\text { comunicativas de } \\
\text { carácter científico: } \\
\text { escritura y oralidad }\end{array}$ & $\begin{array}{l}\text { Conjunto de procesos relacionados con la } \\
\text { comunicación verbal, escrita y, en general, } \\
\text { lingüística, los cuales le permiten al individuo } \\
\text { desenvolverse en diferentes entornos sociales, } \\
\text { en donde es necesaria la comunicación, con el } \\
\text { fin de comunicar, interpretar o expresarse (ver } \\
\text { Colombia Aprende, 2009). }\end{array}$ \\
\hline $\begin{array}{l}\text { b. Competencias } \\
\text { propositivas }\end{array}$ & $\begin{array}{l}\text { Con estas competencias, la persona adquiere } \\
\text { una actitud proactiva hacia el planteamiento de } \\
\text { soluciones, de hipótesis o de diferentes preguntas } \\
\text { que tracen un camino hacia la diversidad de } \\
\text { perspectivas para superar retos (ver Posada } \\
\text { Álvarez, 2004). }\end{array}$ \\
\hline $\begin{array}{l}\text { c. Habilidades en un } \\
\text { segundo idioma: inglés }\end{array}$ & $\begin{array}{l}\text { Como parte de la formación integral de } \\
\text { profesionales, que tengan la capacidad de } \\
\text { absorción, comprensión y proposición de } \\
\text { soluciones para problemáticas en las diversas } \\
\text { realidades globales, nacionales y regionales, } \\
\text { es necesario que se establezcan parámetros } \\
\text { de comunicación a nivel internacional, de tal } \\
\text { forma que los profesionales integrales puedan } \\
\text { entablar un diálogo con la comunidad científica } \\
\text { internacional (acceso a conocimiento global). } \\
\text { Para esto, se deben desarrollar habilidades } \\
\text { en la comunicación en un segundo idioma, } \\
\text { específicamente en inglés, que permite superar } \\
\text { barreras idiomáticas para desarrollar nuevas } \\
\text { tecnologías y propiciar el acercamiento a los } \\
\text { avances de la investigación que se presenta en } \\
\text { otras arenas de la producción del conocimiento. }\end{array}$ \\
\hline
\end{tabular}




\begin{tabular}{|c|c|}
\hline \multicolumn{2}{|c|}{ Competencias y habilidades por fortalecer } \\
\hline d. Pensamiento lógico & $\begin{array}{l}\text { El pensamiento lógico se refiere al proceso } \\
\text { mediante el cual se relacionan y jerarquizan } \\
\text { conceptos, se encadenan proposiciones y, a partir } \\
\text { de ellas, se construyen conclusiones o juicios. } \\
\text { Estas conclusiones pueden ser construidas por } \\
\text { deducción, inducción o analogía. El ejercicio del } \\
\text { pensamiento lógico se apoya en la observación, } \\
\text { la comparación, la clasificación y el análisis } \\
\text { de datos, información, objetos y fenómenos. } \\
\text { Esta forma de pensamiento es esencial para } \\
\text { la construcción y evaluación de argumentos y } \\
\text { para la toma de decisiones (ver Ministerio de } \\
\text { Educación, 2007a). }\end{array}$ \\
\hline $\begin{array}{l}\text { e. Pensamiento } \\
\text { argumentativo }\end{array}$ & $\begin{array}{l}\text { Esta competencia incluye la habilidad del } \\
\text { razonamiento para explicar cómo las diferentes } \\
\text { partes de un proceso se ordenan y se relacionan } \\
\text { entre sí, para lograr cierto efecto o una } \\
\text { conclusión. Al argumentar, se explica el porqué } \\
\text { de las cosas, se justifican las ideas, se dan } \\
\text { razones, se establecen los propios criterios, se } \\
\text { interactúa con el saber (ver Sierra, 2006). }\end{array}$ \\
\hline f. Pensamiento crítico & $\begin{array}{l}\text { El pensamiento crítico permite cuestionar los } \\
\text { fundamentos de las ideas propias y ajenas. Su } \\
\text { ejercicio exige la verificación de la exactitud } \\
\text { de la información en que se basan las opiniones } \\
\text { y juicios, el análisis de los valores y principios } \\
\text { éticos y estéticos implicados, la identificación y } \\
\text { aplicación de criterios, así como la comparación } \\
\text { de diversos puntos de vista, considerando los } \\
\text { intereses de los distintos actores y los contextos a } \\
\text { los que pertenecen. Esta competencia es esencial } \\
\text { para superar prejuicios y estereotipos, y centrar } \\
\text { al individuo en el examen de la validez de sus } \\
\text { ideas y opiniones (ver Ministerio de Educación, } \\
\text { 2007a). }\end{array}$ \\
\hline
\end{tabular}




\begin{tabular}{ll}
\hline & La habilidad del trabajo en equipo supone \\
g. Habilidad de & otros para la realización de actividades, con \\
trabajar en equipos & el propósito de cumplir objetivos comunes, \\
interdisciplinarios y & intercambiando informaciones, asumiendo \\
multidisciplinarios & responsabilidades, resolviendo dificultades \\
& que se presentan y contribuyendo a la mejora y \\
& desarrollo colectivo (ver Torrelles et ál., 2011). \\
\hline & Supone la capacidad y la habilidad de \\
& interiorizar, articular y hacer referencia a \\
& conocimientos producidos en otros entornos, \\
& reconociendo los métodos y técnicas que han \\
permitido construir este conocimiento, al igual & que el contexto en el que ha sido producido (ver \\
conocimiento & Zabala y Arnau, 2014). \\
existente & Navarro Saldaña escribe: "Construcción de \\
& conocimiento es un proceso de elaboración, en el \\
& sentido de que el estudiante selecciona, organiza \\
& y transforma la información que recibe de \\
& diversas fuentes, estableciendo relaciones entre \\
& esa información y sus ideas o conocimientos \\
& previos. Así, el aprendizaje de un nuevo \\
contenido implica que los alumnos le atribuyen \\
un significado a ese contenido, construyendo una \\
representación mental por medio de imágenes \\
o proposiciones verbales, o bien elaborando una \\
teoría o modelo mental con explicaciones de \\
dicho conocimiento. Al construir significados, \\
hay un cambio en los esquemas de conocimientos \\
previos, ya que se introducen nuevos elementos \\
o establecen nuevas relaciones entre los que ya \\
existían" (2015, p. 188). \\
\hline Generación y \\
divulgación del \\
conocimiento
\end{tabular}


Competencias y habilidades por fortalecer

\begin{tabular}{|c|c|}
\hline $\begin{array}{l}\text { j. Conocimiento de las } \\
\text { bases teóricas de la } \\
\text { investigación científica } \\
\text { y los diversos métodos } \\
\text { científicos }\end{array}$ & $\begin{array}{l}\text { Esta competencia implica el conocimiento } \\
\text { básico, la identificación y la habilidad de } \\
\text { discernir y elegir entre diversas herramientas, } \\
\text { métodos y técnicas que componen distintos } \\
\text { métodos científicos (ver Zabala y Arnau, 2014). }\end{array}$ \\
\hline k. Actitud de liderazgo & $\begin{array}{l}\text { Lizarazo Ruiz escribe: "Capacidad de coordinar } \\
\text { y organizar eficazmente equipos de trabajo, } \\
\text { propiciando un adecuado ambiente de } \\
\text { trabajo, orientando y dirigiendo a los demás } \\
\text { para motivarlos e inducirlos a que se llegue } \\
\text { a las metas y objetivos planteados. Así mismo } \\
\text { trasciende y da el ejemplo a través de su } \\
\text { cumplimiento, ética y compromiso" (2015, p. 9). }\end{array}$ \\
\hline $\begin{array}{l}\text { l. Reconocimiento y } \\
\text { aprovechamiento de } \\
\text { oportunidades }\end{array}$ & $\begin{array}{l}\text { Capacidad de buscar, reconocer y entender } \\
\text { necesidades del entorno que se hallen } \\
\text { insatisfechas, o de estructurar soluciones } \\
\text { alternas ante necesidades que no se satisfacen } \\
\text { apropiadamente (ver Buol, 2009). }\end{array}$ \\
\hline m. Iniciativa y constancia & $\begin{array}{l}\text { Capacidad de formular activamente nuevos } \\
\text { proyectos, tomando decisiones oportunas con } \\
\text { criterio propio, proyectando actividades en el } \\
\text { tiempo (corto, mediano y largo plazo) y dándole } \\
\text { sostenibilidad a la ejecución de esas actividades } \\
\text { (ver Educar Chile, 2013). }\end{array}$ \\
\hline n. Resiliencia & $\begin{array}{l}\text { Habilidad y disposición que permiten resistir, } \\
\text { tolerar y adaptarse al cambio, así como hacer } \\
\text { frente a la presión y brindar respuestas ante la } \\
\text { ausencia de resultados (ver Márquez González } \\
\text { et ál., 2016). }\end{array}$ \\
\hline
\end{tabular}


Habilidad relacionada con la capacidad de interpretar las necesidades del otro y de inferir, con acierto, las expectativas, motivaciones y, en general, la forma de actuar del otro, donde se potencian los valores del respeto, de la

ñ. Empatía neutralidad, la escucha, la observación bajo el paradigma de la comunicación positiva. Es una habilidad que combina lo cognitivo y lo emocional para establecer relaciones interpersonales en determinado contexto y en medio de la complejidad de las relaciones humanas, con el fin de proponer soluciones ante cualquier situación. 



\section{El currículo: escenarios estratégicos y líneas de acción}

En el marco de la política para la formación en investigación, juega un papel fundamental el currículo. Etimológicamente, la palabra 'currículo' hace referencia a una raíz latina que significa: 'camino, carrera'. La RAE define la palabra como 'plan de estudios' o 'conjunto de estudios y prácticas destinadas a que el alumno desarrolle plenamente sus posibilidades'. Tanto la raíz etimológica como la definición dada por la RAE dan elementos clave para comprender el concepto de currículo en el contexto de una política para la formación en investigación. Para complementar y clarificar dicho concepto, se retoma el siguiente planteamiento de Lawrence Stenhouse (2003): "Un C. es 
una tentativa para comunicar los principios y rasgos esenciales de un propósito educativo, de tal manera que permanezca abierto a discusión crítica y pueda ser trasladado efectivamente a la práctica" (p. 29).

Desde la perspectiva del Ministerio de Educación, se concibe el currículo como sigue:

Currículo es el conjunto de criterios, planes de estudio, programas, metodologías y procesos que contribuyen a la formación integral y a la construcción de la identidad cultural nacional, regional y local, incluyendo también los recursos humanos, académicos y físicos para poner en práctica las políticas y llevar a cabo el proyecto educativo institucional. (MEN, s. f.)

Al analizar cada una de las definiciones, tanto las etimológicas como epistemológicas, se evidencia que el currículo es el eje de educación, formación y praxis pedagógica, en el cual se conjugan las dimensiones sociológica, antropológica, bioética y epistemológica. Para el caso de la UMNG, estas dimensiones se conocen como currículo SABE (figura 10), que, a partir de la concepción de Stenhouse (2003), se convierten en los rasgos distintivos desde los principios sagrados de Ciencia, Patria y Familia. 
Figura 10. Habilidades, competencias y desempeños desde las dimensiones del currículo SABE

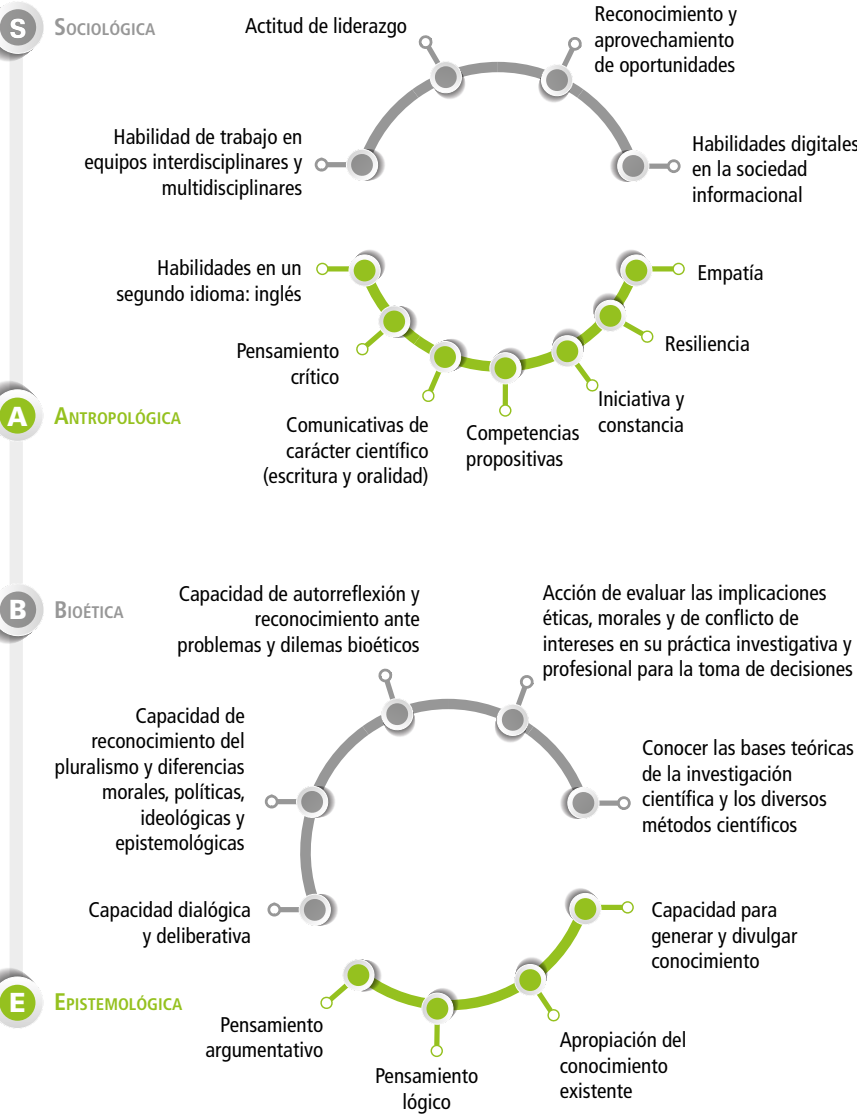


El currículo SABE está constituido por las dimensiones fundamentales que conforman un diseño curricular, a saber:

a. La sociedad, como aquel engranaje humano donde emergen dinámicas y transformaciones culturales, para lo cual debe existir un proyecto claro de educación y formación.

b. El hombre, como individuo y subjetividad, concebido como origen de toda formulación y proyecto curricular.

c. La bioética, concebida como un saber interdisciplinar que ayuda a la comprensión de las dinámicas relacionales holísticas entre hombre, naturaleza, medio ambiente y lo que tenga que ver con la vida y aquello que la preserva y cuida. En el contexto de la investigación, la bioética se entrelaza con la integridad científica y la formación holística, desde el principio neogranadino que reza: "formar ciudadanos íntegros y socialmente responsables". Esta dimensión identifica a la comunidad neogranadina.

d. La epistemología, comprendida como el flujo o conjunto de ciencias, saberes y conocimientos que responden a las exigencias de la sociedad y del hombre.

En resumen:

La escuela tiene por misión poner a disposición [...] una sección del capital intelectual, emocional y técnico con el 
que cuenta la sociedad. Es a ese capital al que he designado como "tradiciones públicas". En nuestra sociedad las escuelas enseñan múltiples y diversas tradiciones públicas. Entre las más importantes se incluyen conjuntos de conocimientos, artes, habilidades, lenguajes, convenciones y valores. (Stenhouse, 2003, p. 33)

La formación en investigación tiene como base la comprensión del hecho educativo como el escenario social donde se transmiten las tradiciones públicas del conocimiento; al mismo tiempo, los individuos cuentan con la versatilidad de la transformación, la creatividad y la innovación, que tienen la tarea de educarlo para adquirir la capacidad de resolución de problemas. Por ende, la apuesta curricular va más allá de la transmisión de saberes, lo que convierte al escenario educativo en la comprensión de los fenómenos como ejes problémicos para los cambios sociales.

Así, el currículo exige ser articulado con las prácticas educativas y formativas, para lo cual Stenhouse recomienda la formulación curricular en cuanto proyecto, estudio empírico y en relación con la justificación (ver tabla 7). 
Tabla 7. Formulación curricular

\begin{tabular}{|c|c|c|}
\hline En cuanto proyecto & $\begin{array}{c}\text { En cuanto estudio } \\
\text { empírico }\end{array}$ & $\begin{array}{c}\text { En relación con la } \\
\text { justificación }\end{array}$ \\
\hline $\begin{array}{l}\text { 1. Principios para } \\
\text { la selección de } \\
\text { contenidos: qué } \\
\text { debe aprenderse y } \\
\text { enseñarse. }\end{array}$ & $\begin{array}{l}\text { Principios con base en } \\
\text { los cuales se estudia y } \\
\text { evalúa el progreso de los } \\
\text { estudiantes. }\end{array}$ & \multirow{4}{*}{$\begin{array}{l}\text { Formulación } \\
\text { de la intención } \\
\text { o la finalidad } \\
\text { del currículo, } \\
\text { formulación que debe } \\
\text { ser susceptible del } \\
\text { examen crítico. }\end{array}$} \\
\hline $\begin{array}{l}\text { 2. Principios para } \\
\text { el desarrollo de } \\
\text { una estrategia de } \\
\text { enseñanza: cómo } \\
\text { debe aprenderse y } \\
\text { enseñarse. }\end{array}$ & $\begin{array}{l}\text { Principios con base en } \\
\text { los cuales se estudia y } \\
\text { evalúa el progreso de los } \\
\text { profesores. }\end{array}$ & \\
\hline $\begin{array}{l}\text { 3. Principios acerca } \\
\text { de la adopción de } \\
\text { decisiones. }\end{array}$ & $\begin{array}{l}\text { Orientación acerca de } \\
\text { la posibilidad de llevar } \\
\text { a cabo el currículo en } \\
\text { diferentes situaciones } \\
\text { escolares y contextos } \\
\text { relativos de alumnos, } \\
\text { así como en ambientes } \\
\text { y situaciones de } \\
\text { estudiantes en grupos. }\end{array}$ & \\
\hline $\begin{array}{l}\text { 4. Principios con base } \\
\text { en los cuales se } \\
\text { diagnostican los puntos } \\
\text { fuertes y débiles } \\
\text { de los estudiantes, } \\
\text { individualmente, y } \\
\text { se diferencian los } \\
\text { principios generales } 1 \text {, } \\
2 \text { y } 3 \text { señalados, a fin } \\
\text { de ajustarse a los casos } \\
\text { individuales. }\end{array}$ & $\begin{array}{l}\text { Información sobre la } \\
\text { variabilidad de los } \\
\text { efectos en diversos } \\
\text { contextos y en distintos } \\
\text { alumnos; además, } \\
\text { comprensión de las } \\
\text { causas de tal variación. }\end{array}$ & \\
\hline
\end{tabular}

Fuente: Stenhouse (2003, p. 30). 
En este contexto conceptual, caracterizado por concebir el currículo como un elemento dinámico en el espacio educativo y formativo, la propuesta del currículo neogranadino SABE pretende responder a las exigencias de la sociedad -dimensión sociológica-; al mismo tiempo, tal propuesta constituye subjetividades -dimensión antropológica-, está conjugada con una dimensión holística del significado de la vida -dimensión bioética- y se encuentra dinamizada por la construcción de ciencias, saberes y conocimientos -dimensión epistemológica-. En otras palabras, la propuesta curricular base de la presente política se plantea según las siguientes preguntas:

a. ¿Qué tipo de hombre, de conocimiento y de bioética, y para qué sociedad, se forja desde la universidad?

b. ¿Qué tipo de individuo exige la sociedad, la bioética y el conocimiento?

c. ¿Qué papel juega la bioética en el contexto de una formulación curricular antropológica y socioepistémica?

d. ¿Qué tipo de ciencias, saberes y conocimientos, y para qué tipo de hombre, sociedad y bioética, se impulsan y dinamizan desde la universidad?

El currículo SABE neogranadino, como eje curricular, da los lineamientos sobre aspectos formativos y educativos concretos, siendo el centro de la preocupación por una educación que supere la mera transmisión de 
contenidos del conocimiento, de tal forma que se fomente el pensamiento crítico, creativo y argumentativo desde una política para la formación en investigación, política que, además, lleve a la construcción y constitución de una cultura para la investigación, aspecto este que comienza en el aula, en el microcosmos pedagógico relacional entre estudiante y profesor. En este sentido, es necesario determinar, definir y proponer las líneas fundamentales para un currículo de formación en investigación desde el macrocurrículo, mesocurrículo, microcurrículo y currículo de formación complementaria.

El macrocurrículo es el escenario estratégico para la identificación y determinación de los problemas socioculturales, antropológicos y bioéticos, ante los cuales se formulan -desde la dimensión epistemológica- áreas del saber y el conocimiento que aporten a la resolución de dichos problemas. Así, la construcción del macrocurrículo parte de la contextualización sociológica, antropológica y bioética; al mismo tiempo, el currículo cuenta con un desarrollo cuya fundamentación es epistemológica, para dar respuesta, desde la educación, a los problemas sociales con una formulación clara de los propósitos de formación: las competencias, las habilidades y los desempeños pertinentes.

En segundo lugar, el mesocurrículo se caracteriza por determinar las áreas específicas de formación con sus 
respectivas competencias, habilidades y desempeños, desde las cuales se articulan los propósitos establecidos en el macrocurrículo, de tal forma que se elabora una cartografía curricular propia dentro de un área de conocimiento. Lo anterior, se conoce en el medio universitario como programa académico. En el mesocurrículo se establece la flexibilidad curricular, junto con su operacionalización y ejecución real.

Por su parte, el microcurrículo es el escenario estratégico donde se produce el hecho educativo, entendido como el encuentro entre profesor y estudiante, proceso de enseñanza y aprendizaje, pedagogía y didáctica. Estos encuentros están dinamizados por la formulación de los planes y actividades en los cursos a desarrollar, es decir, donde se explicitan y formulan los contenidos con su respectiva esencia pedagógica y estrategias didácticas. Así, en el microcurrículo se consideran todos los elementos propios de un syllabus: objetivos, fundamentación dentro del espacio de formación, temáticas o contenidos, estrategias pedagógicas, metodologías y herramientas didácticas para el desarrollo del curso, evaluación y bibliografía. El microcurrículo se encuentra articulado con el mesocurrículo y macrocurrículo, en la medida en que el primero es la operacionalización real de los otros dos currículos. En este sentido, el microcurrículo no puede ser un puente roto respecto a los otros dos currículos, es decir, no 
puede ser, por ejemplo, una formulación desde el parecer del profesor, sino que debe responder a los propósitos formativos nacionales e institucionales.

Ahora bien, el macrocurrículo no se formula solamente para que se desarrolle en las instituciones educativas, $a d$ intra muros de escuelas (colegios, universidades), sino que debe diseñarse pensando también en propuestas de formación complementaria, denominadas en el argot educativo como currículo de formación complementaria. Este corresponde a estrategias curriculares "no formales" pero sí estructurales, encaminadas según el rumbo de los objetivos de formación. Al abordar la definición de currículo de formación complementaria, se observa aquello que no pertenece al currículo o que no se tiene en cuenta en este, de tal forma que tiende a confundirse con el llamado currículo oculto. En el contexto de la presente política de formación en investigación, el currículo de formación complementaria se comprende como las acciones, actividades y estrategias encaminadas a complementar y apoyar los objetivos de formación, las cuales no son ejecutadas dentro de la propuesta formal del mesocurrículo y microcurrículo, pero sí obedecen a la estructura macrocurricular. Así mismo, el currículo de formación complementaria no queda tampoco supeditado a la improvisación pedagógica y didáctica, sino que, por el contrario, responde a un plan 
institucional para fomentar la creatividad, la innovación y la criticidad del estudiante y del profesor.

En este orden de ideas, la comprensión y articulación de los conceptos de interdisciplinariedad, multidisciplinariedad y transdisciplinariedad son esenciales en el diseño curricular, con el fin de fundamentar y ofrecer lineamientos para permitir la flexibilización curricular, especialmente en una política que busca responder desde sus dimensiones, fundamentos pedagógicos y estrategias didácticas a la misión neogranadina: "formar ciudadanos íntegros y socialmente responsables que promuevan la justicia, la equidad, el respeto por los valores humanos y contribuyan al progreso del sector Defensa y a la sociedad en general". Así, la disciplinariedad, la pluridisciplinariedad, la interdisciplinariedad y la transdisciplinariedad son las cuatro flechas de un mismo arco: el conocimiento (ver Nicolescu, 1998); también, aquellas hacen parte del contexto social, de los flujos históricos y las dinámicas culturales donde subyacen y surgen las situaciones problemáticas que exigen del sistema educativo fomentar y desarrollar la formación en ciencias, saberes y conocimientos pertinentes, así como facilitar y dinamizar la flexibilidad curricular, la cual es entendida por el Ministerio de Educación Nacional de la siguiente forma:

Un currículo flexible es aquel que mantiene los mismos objetivos generales para todos los estudiantes, pero da 
diferentes oportunidades de acceder a ellos: es decir, organiza su enseñanza desde la diversidad social, cultural de estilos de aprendizaje de sus alumnos, tratando de dar a todos la oportunidad de aprender. (MEN, 2007b)

En este sentido, las cuatro flechas del conocimiento son un elemento indispensable para ejecutar y promover un currículo flexible; esto significa que el hecho educativo y la práctica pedagógica son los escenarios estratégicos para llevar a cabo una formación disciplinar, interdisciplinar, pluridisciplinar y transdisciplinar, es decir, que el contenido del conocimiento para la formación en investigación es un elemento integrador y holístico. Esto lleva a preguntarse por la razón y el propósito de una flexibilidad curricular y académica. Al respecto, escribe Pedroza:

La universidad necesita revisar su modelo de organización para responder a la dinámica del conocimiento y del cambio contextual: la refuncionalización tiene que orientarse al fomento de la intelectualización de la problemática humanística, social, política, cultural y económica. Consideramos la posibilidad de flexibilizar académicamente a la universidad: superar las barreras dominantes impuestas por la institucionalización del conocimiento con base en disciplinas.

La flexibilidad académica la definimos como: el proceso de intercomunicación disciplinaria orientado a facilitar la 
movilidad de los actores académicos, acelerar los flujos de comunicación, conectar el conocimiento con la acción y democratizar la regulación del trabajo académico. Este proceso tiene que ser acompañado con la creación de redes de conocimiento: agrupamiento de las interacciones internas y externas de los actores universitarios de las distintas áreas del saber. (2005, p. 10)

Así, la flexibilidad curricular se caracteriza por favorecer la movilidad de los actores universitarios, que en el contexto de la educación universitaria deben destacarse por sus habilidades, capacidades y desempeños con bases disciplinares, interdisciplinares, pluridisciplinares y transdisciplinares. Esto se fundamenta en el llamado hecho por la Unesco en la "Declaración mundial sobre la educación superior en el siglo XXI: visión y acción”:

Artículo 5. Promoción del saber mediante la investigación en los ámbitos de la ciencia, el arte y las humanidades y la difusión de sus resultados

a. El progreso del conocimiento mediante la investigación es una función esencial de todos los sistemas de educación superior que tienen el deber de promover los estudios de postgrado. Deberían fomentarse y reforzarse la innovación, la interdisciplinariedad y la transdisciplinariedad en los programas, fundando las orientaciones a largo plazo en los objetivos y necesidades sociales y culturales. 
Lo anterior se puede plantear de forma esquemática, como se aprecia en la figura 11.

El papel sociocultural, educativo y formativo de la Universidad no se limita solamente a la transmisión de contenidos del conocimiento, y en esta medida la docencia no es un sistema de reproducción de saberes; en cambio, se considera que la Universidad tiene la responsabilidad socioeducativa de formar para la resolución de problemas existentes o que pueden emerger en las dinámicas sociales y culturales. En este contexto, la investigación es el espíritu de cualquier institución universitaria. Por ende, el currículo de una universidad debe tener un significativo componente de formación para la investigación, desde la interdisciplinariedad y transdisciplinariedad.

Para efectos de la presente política, la concepción de interdisciplinariedad no se limita solamente a la necesidad de interrelacionar saberes, conocimientos y ciencias, sino que va más allá:

La interdisciplinariedad significa defender un nuevo tipo de persona más abierta, flexible, solidaria, democrática y crítica. El mundo actual necesita personas con una formación cada vez más polivalente para hacer frente a una sociedad donde la palabra cambio es uno de los vocablos más frecuentes y donde el futuro tiene un grado de imprevisibilidad como nunca en otra época de la historia de la humanidad. (Torres, 2006, p. 48) 


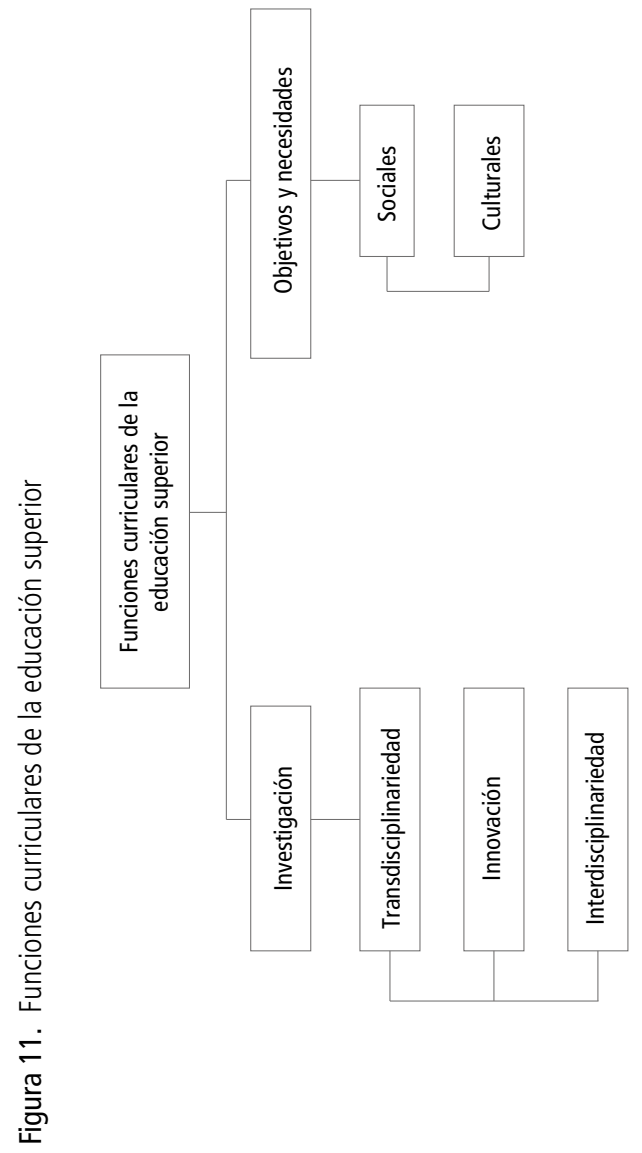


Esta concepción nos permite abrir el espectro y horizonte de comprensión de la interdisciplinariedad como elemento curricular para la flexibilidad, de tal forma que se supera la idea según la cual la interdisciplinariedad es la mera capacidad de diálogo entre ciencias y saberes; esto descarta u obvia el diálogo con las dinámicas de los procesos sociales, que solicitan un diseño curricular distinto, más en el ámbito de la formación universitaria con énfasis en la investigación. Es decir, un currículo flexible interdisciplinar es aquel que facilita el diálogo entre las dimensiones del currículo SABE neogranadino, para el caso de nuestra política de formación en investigación. Esta definición y concepción es complementada con la postura de Nicolescu:

La interdisciplinariedad tiene un objetivo diferente a la multidisciplinariedad. Se refiere a la transferencia de métodos de una disciplina a la otra. Por ejemplo, una transfiere los métodos de la física nuclear a la medicina, y esto lleva a la aparición de nuevos tratamientos para el cáncer. Al igual que la multidisciplinariedad, la interdisciplinariedad desborda las disciplinas, pero su objetivo sigue estando dentro del marco de la investigación disciplinaria. (2013)

La disciplinariedad, la interdisciplinariedad y la transdisciplinariedad, triada epistemológica emergente a 
mediados del siglo XX, se convierten en ejes curriculares fundamentales para el ejercicio socioeducativo y formativo de la Universidad; en la presente política, además, son ejes para pensar y repensar la formación para la investigación. En este orden de ideas, se comprende la transdisciplinariedad como se expone a continuación:

Como indica el prefijo Trans, la transdisciplinariedad se preocupa por aquello que está entre las disciplinas, a través de ellas y más allá de toda disciplina. Su objetivo es la comprensión del mundo actual, en el cual uno de los imperativos es la unidad del conocimiento. La palabra en sí es bastante reciente: fue introducida por primera vez por Jean Piaget en 1970. (Piaget, citado en Nicolescu, 2013)

Al ser su objetivo "la comprensión del mundo", deja de ser una propuesta de carácter netamente epistemológico, entrelazándose más bien con los aspectos y dinámicas de lo educativo y lo formativo. Esto quiere decir que se concibe la transdisciplinariedad como un enfoque educativo que se diferencia del enfoque educativo disciplinar, como lo expone Nicolescu (ver tabla 8). 
Tabla 8. Educación disciplinaria vs. educación transdisciplinaria

\begin{tabular}{l|l}
\hline \multicolumn{1}{c|}{ Educación disciplinaria (ED) } & \multicolumn{1}{c}{ Educación transdisciplinaria (ET) } \\
\hline In vitro & In vivo \\
\hline Un nivel de la realidad & Varios niveles de la realidad \\
\hline Mundo externo (objeto) & $\begin{array}{l}\text { Correspondencia entre el mundo } \\
\text { externo (objeto) y el mundo interno } \\
\text { (sujeto) }\end{array}$ \\
\hline Acumulación de conocimiento & Comprensión \\
\hline Inteligencia analítica & $\begin{array}{l}\text { Nuevo tipo de inteligencia: armonía } \\
\text { entre mente, emociones y cuerpo }\end{array}$ \\
\hline Lógica binaria & Lógica del tercero excluido \\
\hline Verdad absoluta/Falsedad absoluta & Verdad relativa \\
\hline Orientada hacia el poder y la posesión & $\begin{array}{l}\text { Orientada hacia el asombro y el acto } \\
\text { de compartir }\end{array}$ \\
\hline Exclusión de valores & Inclusión de valores \\
\hline
\end{tabular}

Fuente: Nicolescu (2013).

La educación con enfoque transdisciplinar exige que el currículo sea flexible, de tal forma que se lleve a cabo una práctica pedagógica cimentada en la resolución de problemas, así como un docente que se convierte en el gestor de líderes que ven, en los distintos niveles de la realidad, la posibilidad de crear, innovar y proponer alternativas para el mejoramiento de la calidad de vida, con un saber y conocimiento contextualizado, cimentado en procesos de formación para la investigación con prospectiva sociocultural. 
Para ello se propone organizarlo [el currículo] con un Modelo de Generación de Nuevos Conocimientos y Competencias Académicas, articulado en tres áreas: área básica de información, área básica de formación y área básica de autoaprendizaje. Cada una de estas áreas contiene ámbitos de dominio cognitivo, práxico, valorativo y actitudinal que en su conjunto potencian la creatividad y la ética en la toma de decisiones. (Herrera y Dridiksson, 2010)

Información, formación y autoaprendizaje, como lo expone el autor, permiten descentrar el ejercicio de la formación universitaria de la clásica concepción de la profesionalización, dependiente de una práctica docente limitada a la mera transmisión de contenido, como paradigmático enciclopedismo. Construir un currículo flexible para la formación en investigación, exige un cambio de paradigma educativo, que abarca desde lo pedagógico, pasando por lo didáctico, pero, ante todo, en el contexto del SABE neogranadino, considerando la importancia del sentido de la educación en el contexto actual, donde el autoaprendizaje permite y favorece que el estudiante descubra y construya su propio proceso. Así, la flexibilidad curricular es caracterizada por lo siguiente: a) es abierta, pues se centra en metodologías y didácticas no parametrales y de aula invertida; b) fomenta la interdisciplinariedad y transdisciplinariedad; c) contextualiza el 
proceso de enseñanza-aprendizaje desde propuestas de formación versátiles y flexibles; d) dinamiza los procesos de investigación interdisciplinares y transdisciplinares con responsabilidad y conciencia social, y e) potencializa el trabajo educativo y formativo basado en la resolución de problemas en interrelación con la formación por contenidos disciplinares e interdisciplinares.

La construcción de un proyecto curricular, fundamentado en la flexibilidad y cimentado en la interdisciplinariedad y transdisciplinariedad, requiere el planteamiento de estrategias de evaluación holística, es decir, donde se evalúan no solamente los procesos que se ejecutan dentro del aula, sino también todo el proceso curricular. De esta forma, tal proyecto incluye a los actores pedagógicos e involucra y compromete a toda la comunidad educativa; además, en el caso de la presente política, se incluye a los actores de los procesos de investigación. Por ende, se trata de una formación contextual basada en lo descrito a continuación:

[...] el principio de flexibilidad puede permitirles a las instituciones de educación superior aprender a orientar e identificar y a orientar la búsqueda de soluciones en procura del fortalecimiento de sus propuestas innovativas [sic] que, con todos sus problemas, puedan tener trascendencia institucional. (Díaz, 2002) 
Así, en el marco de esta política, el escenario curricular del currículo SABE neogranadino concibe la educación y formación en materia de investigación, y en esta medida es un agente social clave y estratégico, desde el cual se debe responder a las exigencias del individuo actual, la sociedad contemporánea, las dinámicas emergentes bioéticas y las ciencias, los saberes y conocimientos que favorezcan el objetivo de cumplir la misión de la Universidad, que consiste en formar ciudadanos íntegros y socialmente responsables.

Tabla 9. Objetivos específicos según el escenario estratégico

\begin{tabular}{|c|c|}
\hline Microcurrículo & $\begin{array}{l}\text { - Promover la cultura investigativa a través del uso de } \\
\text { metodologías y estrategias pedagógicas orientadas } \\
\text { al desarrollo de competencias relacionadas con la } \\
\text { investigación formativa. } \\
\text { - Incentivar en la población profesoral el uso de } \\
\text { estrategias de aprendizaje por descubrimiento y } \\
\text { construcción en la elaboración de sus syllabus. }\end{array}$ \\
\hline Mesocurrículo & $\begin{array}{l}\text { - Articular espacios, actividades y estrategias de fomento } \\
\text { de la formación para la investigación, la innovación y el } \\
\text { emprendimiento con el currículo actual de la umNG. } \\
\text { - Impulsar la formación de profesionales con la } \\
\text { capacidad, la habilidad y la iniciativa de trabajar en } \\
\text { equipos multidisciplinares e interdisciplinares. }\end{array}$ \\
\hline $\begin{array}{l}\text { Currículo de } \\
\text { formación } \\
\text { complementaria }\end{array}$ & $\begin{array}{l}\text { - Fortalecer la capacidad investigativa, innovadora y } \\
\text { emprendedora de los estudiantes de la uMNG. } \\
\text { - Fomentar la formación para la investigación, } \\
\text { la innovación y el emprendimiento, así como la } \\
\text { investigación formativa en los profesores de la UMNG. } \\
\text { - Establecer las estrategias necesarias para alimentar } \\
\text { la formación de profesionales con sentido de } \\
\text { responsabilidad ética, social y ambiental. }\end{array}$ \\
\hline
\end{tabular}




\subsection{Microcurrículo}

Este escenario estratégico se concentra principalmente en los procesos de educación y aprendizaje, relacionados con la formación que se da en el aula con miras a la investigación, la innovación y el emprendimiento. De esta forma, se diseñarán actividades que involucran el espacio del aula como escenario de oportunidad para fomentar la formación para la investigación, la innovación y el emprendimiento. Las apuestas de este escenario estratégico van, por un lado, hacia la incursión en metodologías y estrategias de aprendizaje por construcción y descubrimiento, que ayuden a fortalecer las competencias y habilidades mencionadas anteriormente en las asignaturas del Plan de Estudios; por otro lado, van hacia la construcción de vínculos curriculares entre asignaturas, especialmente en los primeros semestres, en donde puedan reunirse grupos multidisciplinares y aunarse esfuerzos entre diversas materias para asegurar una transversalidad de la formación para la investigación.

\subsubsection{Línea de acción: estrategias pedagógicas y} herramientas de aprendizaje en las asignaturas

En cada Plan de Estudios, la dirección del programa, bajo el liderazgo de las decanaturas correspondiente, debe realizar las siguientes actividades: 
a. Identificar un grupo de seguimiento por cada Facultad y programa, y realizar agrupamientos por asignaturas para la gradualidad del programa.

b. Determinar las asignaturas del Plan de Estudios (incluyendo electivas), en las que se puedan implementar las estrategias y metodologías activas para desarrollar el aprendizaje por descubrimiento.

- Realizar talleres de reconocimiento de escenarios (asignaturas) para la implementación de esas estrategias.

c. Estimular en los profesores el uso de estas estrategias y metodologías. Tener en cuenta lo siguiente:

- Capacitar a docentes en diferentes estrategias y metodologías para desarrollar el aprendizaje por descubrimiento, las cuales se presentan a continuación:

- Metodología por proyectos

- Aprendizaje basado en problemas

- Estudios de caso

- Seminarios (conforme al esquema alemán)

- Escritura de ensayos

- Aula invertida

- Otras

d. Definir las características que debe tener el perfil de un profesor con capacidad para fomentar la formación para la investigación, la innovación y el emprendimiento. Se proponen los siguientes: 
- Conocimiento de las metodologías activas, basadas en el descubrimiento de acuerdo con sus disciplinas.

- Conocimiento y apropiación de las nuevas tecnologías de la información.

- Conocimiento de los mecanismos de acceso, búsqueda y categorización del conocimiento en bases de datos y bibliotecas.

- Conocimiento y manejo del método científico.

- Disposición a ser colaborativo y cooperativo.

- Fomento y práctica de la autonomía académica y científica.

- Capacidad para fomentar el trabajo en equipo (también interdisciplinario y multidisciplinario).

- Reflexividad analítica sobre procesos y conocimientos utilizados o generados.

e. Realizar capacitaciones a profesores de la UMNG sobre estas estrategias, su diseño y aplicación dentro del microcurrículo.

f. Ejecutar actividades de mapeo de asignaturas de cada Facultad para fomentar la formación para la investigación, la innovación y el emprendimiento con el descubrimiento y desarrollo de competencias y habilidades.

La implementación de estas líneas de acción partirá de un análisis preliminar de las asignaturas y su aplicación 
en grupos de asignaturas por niveles, y se realizará en un proceso cíclico de implementación, validación y medición.

6.1.2 Metodología de la Investigación como introducción a la formación para la investigación, la innovación y el emprendimiento

La asignatura denominada Metodología de la investigación ha sido uno de los espacios de formación curricular cuyo objetivo principal consiste en realizar una introducción a distintos métodos científicos y pensamientos científicos, dependiendo de las áreas disciplinares que se desarrollen. A partir de ella, se debería iniciar un proceso de desarrollo y descubrimiento - a través de todo el currículo- de competencias y habilidades relacionadas con la formación para la investigación de los estudiantes de la UMNG. Se proponen las siguientes actividades con el propósito de fortalecer la asignatura mencionada:

- Guiar la construcción de syllabus de las asignaturas sobre metodología de la investigación, de tal forma que aquellos sean apropiados para la iniciación de los estudiantes en las nociones, los métodos y las técnicas básicas de la investigación en las distintas áreas disciplinares. En este sentido:

- Realizar talleres de construcción del syllabus de la asignatura Metodología de la investigación. 
- Diseñar una estrategia basada en el aula invertida para que los estudiantes desarrollen los conocimientos antes de la clase, por medio de ayudas audiovisuales y lecturas; así mismo, desarrollar talleres que permitan la consolidación del aprendizaje mediante el uso de metodologías activas.

- Promover la comunicación de los profesores encargados semestralmente de la asignatura Metodología de la investigación con los profesores encargados de asignaturas introductorias a las áreas generales del conocimiento disciplinar, para propiciar el desarrollo conjunto de programas o actividades.

- Socializar el syllabus de la asignatura Metodología de la investigación en los programas y las Facultades.

- Fortalecer la imagen de la asignatura Metodología de la investigación ante las Facultades, el cuerpo estudiantil y los profesores.

- Hacer que la metodología de la investigación tenga componentes transdisciplinares que permitan a estudiantes de diversas disciplinas interactuar, crear sinergias e identificarse por medio de la experiencia. 
6.1.3 Otras asignaturas: Seminario de Investigación, Prácticas de Investigación y Metodología de la Investigación II

Las asignaturas de los diversos Planes de Estudios que están relacionadas con el fortalecimiento de la formación para la investigación, la innovación y el emprendimiento, deben ser revisadas desde los syllabus, al igual que la asignatura Metodología de la Investigación. Para llevar a cabo lo anterior, se proponen las siguientes actividades:

- Identificar las asignaturas que tengan como propósito la formación para la investigación, la innovación y el emprendimiento.

- Identificar el perfil del profesor que dicta este tipo de asignaturas, el cual debería tener las siguientes características:

- Suficiencia investigativa (preferiblemente en el nivel de doctorado), constancia en la práctica de la investigación y reconocimiento de la labor docente por parte de su programas y Facultad.

- Producción investigativa reconocida.

- Guiar la construcción de los syllabus de las asignaturas.

- Realizar talleres de construcción de syllabus.

- Diseñar una estrategia basada en el aula invertida, para que los estudiantes desarrollen los 
conocimientos antes de la clase, por medio de ayudas audiovisuales y lecturas; así mismo, desarrollar talleres que permitan la consolidación del aprendizaje, mediante el uso de metodologías activas.

- Diseñar las asignaturas para ser desarrolladas en el idioma inglés, y así fortalecer la política de bilingüismo. 


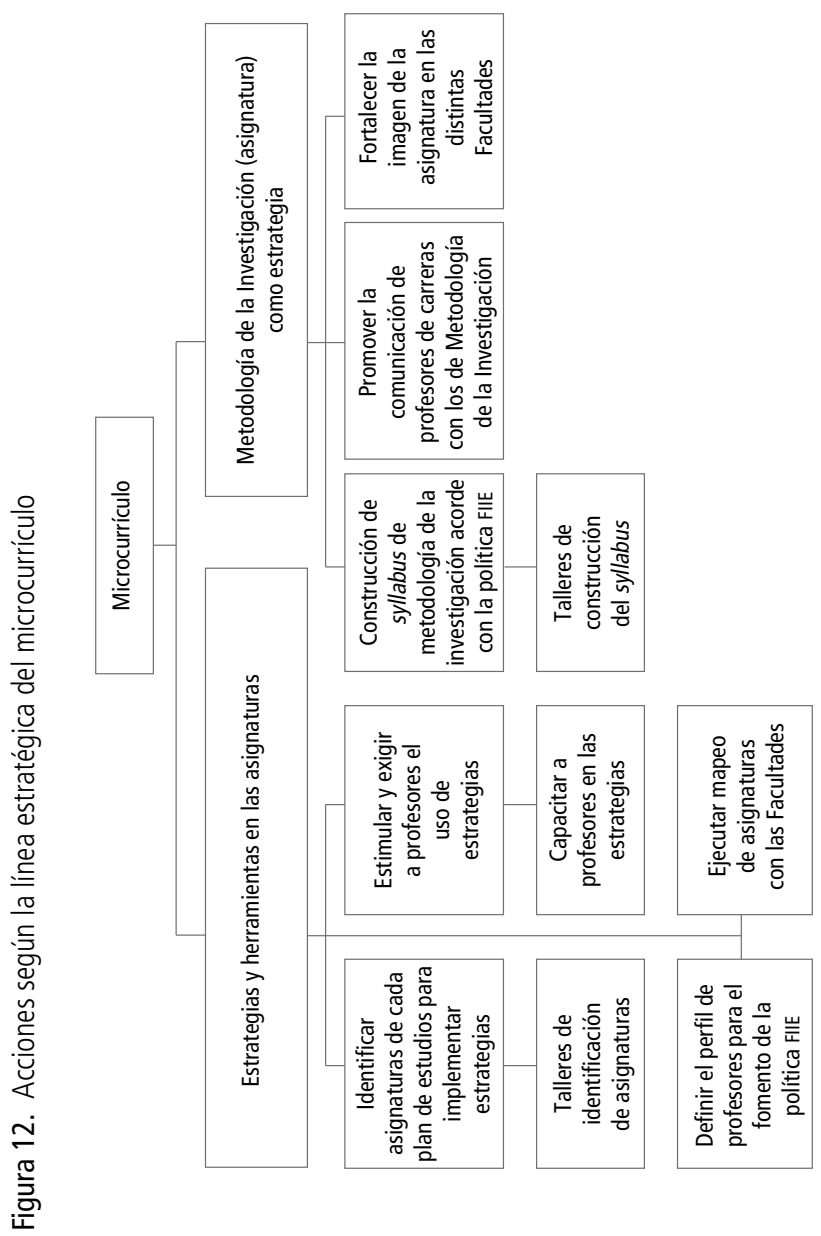




\subsection{Mesocurrículo: Plan de Estudios}

La segunda línea estratégica busca encontrar toda oportunidad que exista en los Planes de Estudios actuales de la UMNG, para crear allí los espacios para el fomento de la formación para la investigación, la innovación y el emprendimiento. Estos espacios, como se propone acá, tienen la función de asegurar que se proporcione una transversalidad al desarrollo de las competencias y habilidades señaladas antes, es decir, que estas se puedan desarrollar durante un proceso a lo largo de distintos flujos del Plan de Estudios, más que ser asuntos únicamente relegados al escenario de la asignatura.

6.2.1 Línea de acción: áreas (líneas) de énfasis en investigación, innovación y emprendimiento

En el Plan de Estudios se pueden ofrecer líneas con un énfasis en investigación, innovación y emprendimiento, a través de los cursos y asignaturas específicas disponibles en dichos planes y de electivas complementarias, dedicadas a la formación para la investigación, la innovación y el emprendimiento. Las asignaturas que conforman esta línea de profundización en investigación, innovación y emprendimiento deben ser ofrecidas de forma general en todos los programas, y deben ser diseñadas conjuntamente por Facultades, centros de investigación, 
la Vicerrectoría Académica y la Vicerrectoría de Investigaciones. Particularmente, se incluirían componentes interdisciplinares y transdisciplinares que permitan la flexibilidad, para que el estudiante pueda tener una oferta amplia. Las acciones consideradas para diseñar las asignaturas son las siguientes:

- A través de capacitaciones y talleres, orientar a las Facultades en la construcción de asignaturas relacionadas con la investigación, la innovación y el emprendimiento, según las distintas áreas disciplinares.

- Diseñar una línea genérica (general) de profundización.

- Diseñar cursos de gestión de la innovación, emprendimiento innovador, ciencias experimentales, propiedad intelectual, proyectos integradores, historia de las ciencias, ética, bioética e integridad científica, gestión del emprendimiento, escritura científica, etc.

- Acompañar en la construcción de syllabus de asignaturas de formación para la investigación, la innovación y el emprendimiento.

- Establecer un grupo de asignaturas que se impartan en inglés para asegurar las competencias educativas en otras lenguas.

- Proponer un incentivo a los estudiantes que decidan tomar esta línea de profundización, como puede ser la mención al obtener el título. (Evaluar si existe la 
capacidad financiera y administrativa de otorgar otro tipo de incentivo bajo esta línea).

- Fomentar la participación de los semilleros de investigación en estas líneas de profundización.

6.2.2 Línea de acción: transversalidad e interdisciplinariedad desde el Plan de Estudios

Esta línea de acción requiere una lectura cuidadosa de los Planes de Estudios por parte de las Facultades, con el objetivo de trazar estrategias de transversalidad en aquellos, esto para asegurar la transversalidad, la transdisciplinariedad y la interdisciplinariedad. Con el propósito de desarrollar esta línea, se consideran las siguientes actividades:

- Identificar, en cada Plan de Estudios, la posibilidad de articular asignaturas de diferentes semestres.

- Flexibilizar los prerrequisitos en las asignaturas complementarias.

- Realizar capacitaciones a profesores y directores de programa sobre estrategias de fomento al trabajo interdisciplinar y multidisciplinar en el Plan de Estudios.

- Establecer posibles líneas de encuentro entre las asignaturas de un programa con las asignaturas de otros 
programas, con el fin de desarrollar tareas o proyectos conjuntamente.

- Realizar talleres de identificación de asignaturas que se puedan articular bajo la estrategia del mesocurrículo.

- Ejecutar workshops de construcción simultánea de syllabus que promuevan la articulación entre asignaturas bajo esta estrategia.

- Generar estrategias de articulación curricular entre distintas Facultades para realizar proyectos con estudiantes de distintos semestres.

- Promover incentivos académicos (créditos o inscripción de materias) a los estudiantes que se vinculen a la articulación de asignaturas de distintos semestres (transversalmente) o programas (interdisciplinarmente).

- Capacitar a los profesores en temas específicos de la innovación y el emprendimiento en Colombia. 


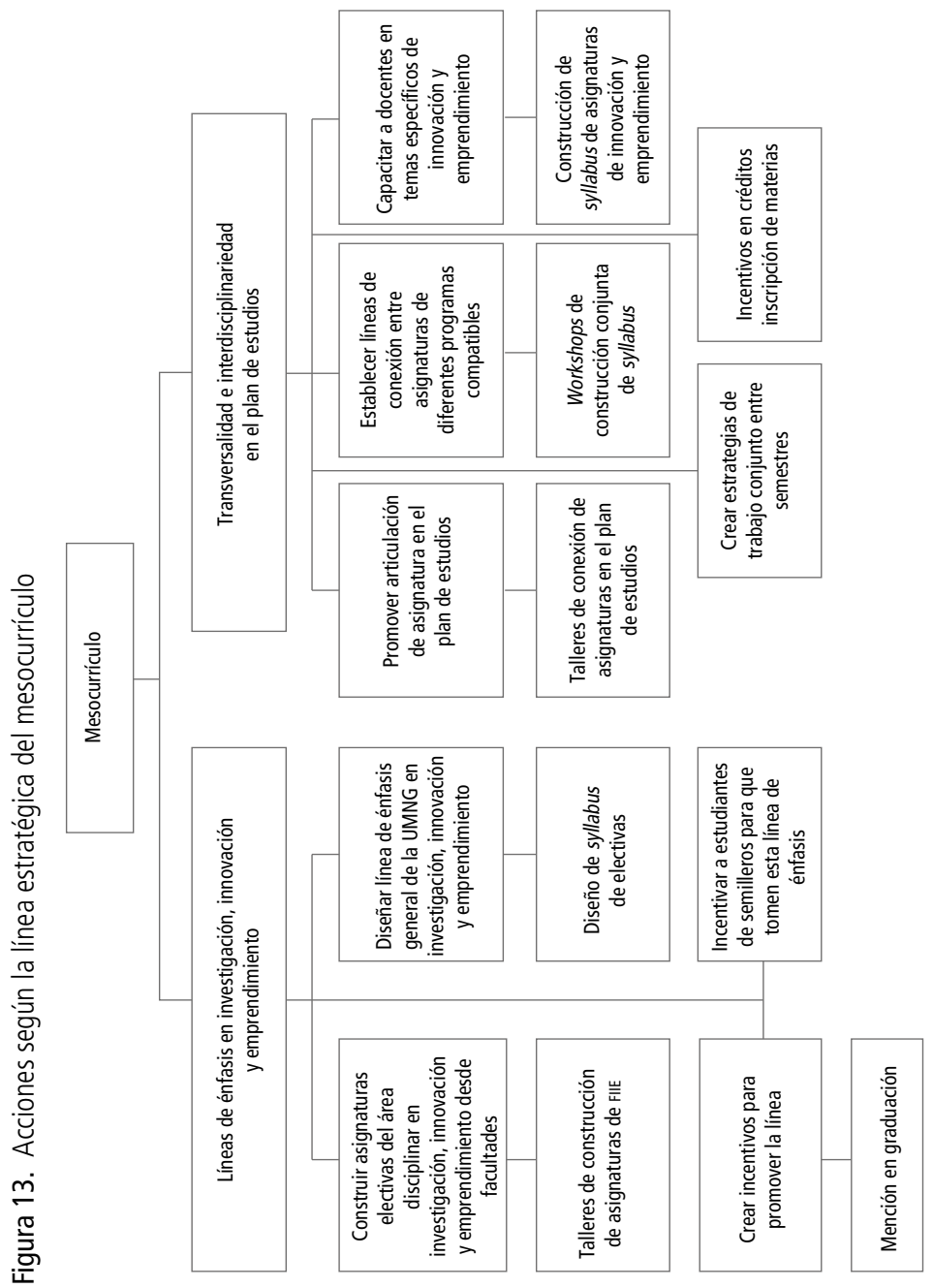




\subsection{Currículo de formación complementaria}

Bajo este escenario estratégico, se busca hacer una revisión de espacios existentes, como son los casos de los semilleros de investigación y los proyectos de iniciación científica (PIC). Tal revisión no implica una reestructuración de los fundamentos institucionales u organizacionales de los semilleros y los PIC (es decir, estos no quedarían sujetos a reforma), sino que tiene como fin proponer un enfoque diferente de dichos espacios. Las actividades que se realizan bajo las líneas de acción en el escenario extracurricular pretenden, adicionalmente, dar sustento al monitoreo y a la evaluación de esta política FIIE.

\subsubsection{Línea de acción: semilleros de investigación}

Se proponen las siguientes acciones respecto a los semilleros:

- Desarrollar un manual de semilleros que tenga todos los elementos necesarios para la conceptualización, creación y seguimiento de este espacio.

- Promover el desarrollo de los semilleros de investigación según unas fases, que pueden ser las siguientes:

- Fundamentación y bases de la investigación: se desarrollan competencias y habilidades comunicativas, así como el pensamiento lógico, la apropiación del conocimiento existente, etc. Un producto de esta primera fase, por ejemplo, puede ser un estado 
del arte. En esta fase es importante identificar cursos, talleres y actividades extracurriculares que permitan desarrollar competencias y habilidades de una manera activa y atractiva. Algunos ejemplos de estos cursos pueden ser: pensamiento creativo, comunicación, gestión de grupos, etc.

- Exploración: se desarrollan el pensamiento argumentativo, el conocimiento y la exploración del método, y el pensamiento científico, entre otras capacidades. Como resultado de esta fase, puede obtenerse la construcción de un anteproyecto de investigación.

- Implementación: se desarrolla el pensamiento crítico, la habilidad para trabajar en equipos multidisciplinares y la conciencia de responsabilidad ética y social. Como resultado de esto, puede obtenerse la iniciación de un PIC.

- Divulgación: se desarrollan competencias y habilidades como la capacidad de generar y divulgar conocimiento, y se perfeccionan las demás. El resultado de esto puede ser la finalización del PIC, la producción de un artículo o ponencia y su respectiva presentación.

- Incentivar a los estudiantes participantes de semilleros a tomar las líneas de profundización en investigación, innovación y emprendimiento. 
- Impulsar una articulación de los ejercicios y tareas designadas en el semillero con las tareas asignadas en las asignaturas articuladas en las líneas anteriores, a modo de incentivo académico.

- Crear espacios alternos de encuentro entre asistentes graduados y estudiantes para fortalecer y acompañar procesos o fases del semillero.

\subsubsection{Línea de acción: proyectos de iniciación científica}

Se proponen las siguientes acciones respecto a los PIC:

- Fomentar la vinculación de los PIC con las fases de los semilleros; así mismo, definir y conceptualizar estos proyectos, e incluirlos como objetivo de las fases de formación. Como actividad implícita, se tiene:

- Vincular los PIC a los semilleros de investigación, específicamente con estudiantes que se encuentren en un estado avanzado de participación (por antigüedad o desarrollo de algún anteproyecto). Los estudiantes deberán vincularse a un PIC.

- Brindar la posibilidad de que asistentes graduados puedan participar activamente (excluyendo el componente financiero) en los PIC.

- Reevaluar los objetivos del cumplimiento de los profesores en el marco de los PIC. 
- Revisar el programa de incentivos (la descarga horaria) a profesores que tienen a su cargo semilleros y PIC simultáneamente.

6.3.3 Línea de acción: articulación de la formación para la investigación con opciones de grado que tengan un énfasis en investigación

Se proponen las siguientes acciones:

- Identificar las diferentes opciones de grado que se articulan con procesos como, por ejemplo, semilleros de investigación, trabajos de grado, auxiliares de investigación, etc., e identificar cómo se articulan, cuál es su conceptualización y cuáles son los requisitos mínimos.

- Identificar estrategias de pasantías en investigación como opciones de grado, en las modalidades de pasantía de investigación internacional o pasantía de investigación empresarial. Para este caso, definir la articulación necesaria con los semilleros, la conceptualización, los incentivos y los requisitos.

6.3.4 Línea de acción: participación de los estudiantes de pregrado en proyectos de investigación científica

Se proponen las siguientes acciones:

- Fomentar la participación de estudiantes como auxiliares de investigación, mediante la socialización 
permanente y las convocatorias de investigación que exijan la vinculación de los alumnos.

- Formalizar los aspectos que deben tenerse en cuenta para la aprobación de trabajos de grado vinculados con proyectos de investigación.

6.3.5 Línea de acción: formación para la investigación en maestrías y doctorados de la UMNG

Se proponen las siguientes acciones:

- Fortalecer las estrategias de participación de los estudiantes como auxiliares de investigación de posgrados.

- Fomentar desde las convocatorias la vinculación de estudiantes de posgrado, así como la producción intelectual conjunta entre estudiantes de maestría y doctorado.

- Definir posibles espacios de convocatorias para el desarrollo de proyectos de estudiantes de posgrado.

- Definir posibles mecanismos de fomento para proyectos que vinculen asistentes graduados de segundo año.

- Establecer estrategias de fomento de pasantías internacionales de investigación ofrecidas en una segunda lengua.

6.3.6 Línea de acción: otros espacios de participación

Se observa la necesidad de promover, promocionar y fortalecer la participación de la comunidad neogranadina en 
espacios de encuentro de corte académico, de investigación y de formación. Se proponen las siguientes acciones:

- Realizar talleres de formación profesoral y estudiantil relacionados con la formación para la investigación, la innovación y el emprendimiento, por ejemplo:

- Talleres de innovación y emprendimiento social, económico y ambiental.

- Promover activamente, desde Facultades, programas y vicerrectorías, la participación de la comunidad neogranadina (estudiantes, profesores, directivos, administrativos -cuando sea el caso-, egresados y asistentes graduados) en espacios académicos, científicos, investigativos y formativos destinados a la divulgación del conocimiento.

- Invitar población estudiantil y profesoral de otras universidades a eventos dentro de la UMNG.

- Fomentar espacios de socialización de avances de investigación.

- Instaurar ferias de exposición de avances de proyectos realizados en las asignaturas del Plan de Estudios con el enfoque de la formación para la investigación, la innovación y el emprendimiento. 
- Identificar oportunidades de generación de espacios de participación por parte de semilleros de investigación o grupos de investigación.

- Crear un espacio de exposición para los grupos de investigación, con el propósito de difundir sus avances y generar discusión académica.

- Construir con otras instituciones espacios de participación, por ejemplo:

- Congresos de uso de estrategias de investigación formativa.

- Seminarios sobre formación para la investigación, la innovación y el emprendimiento. 


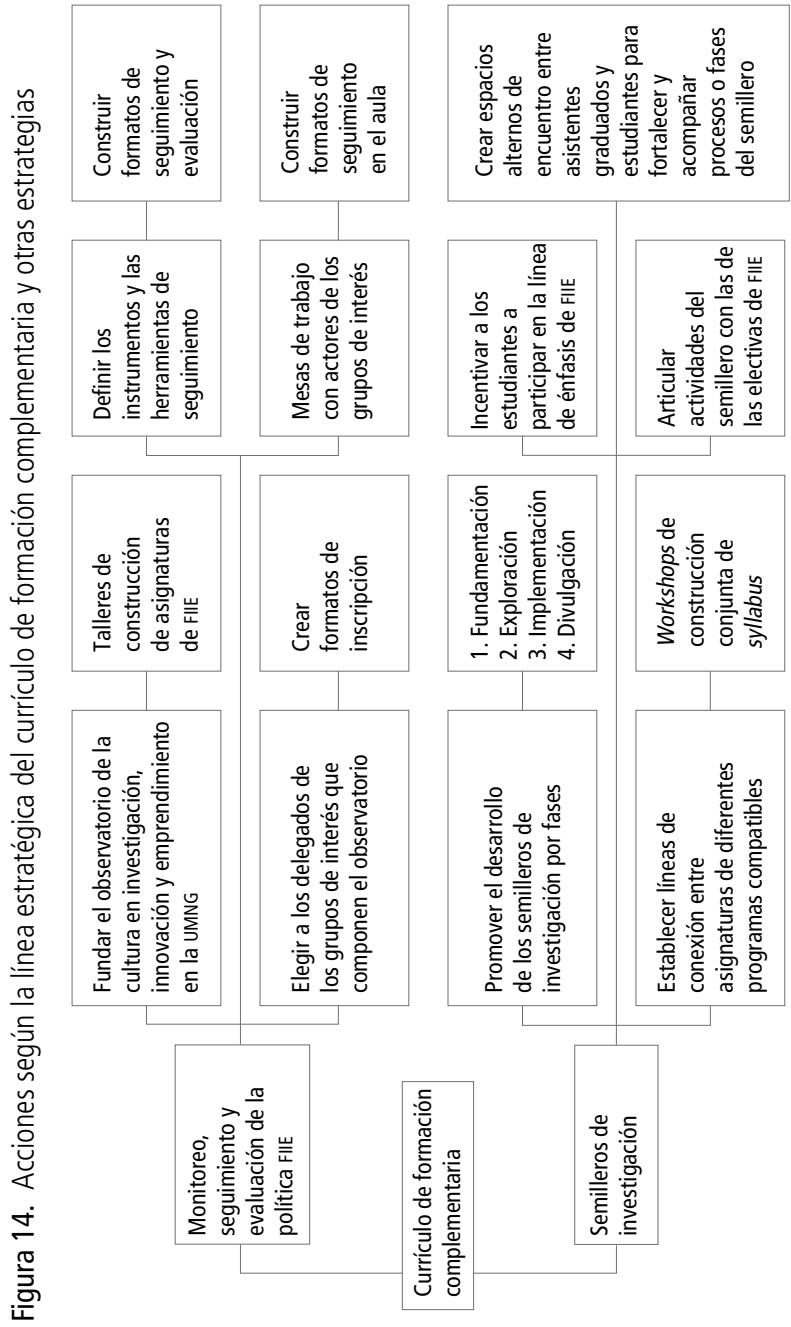




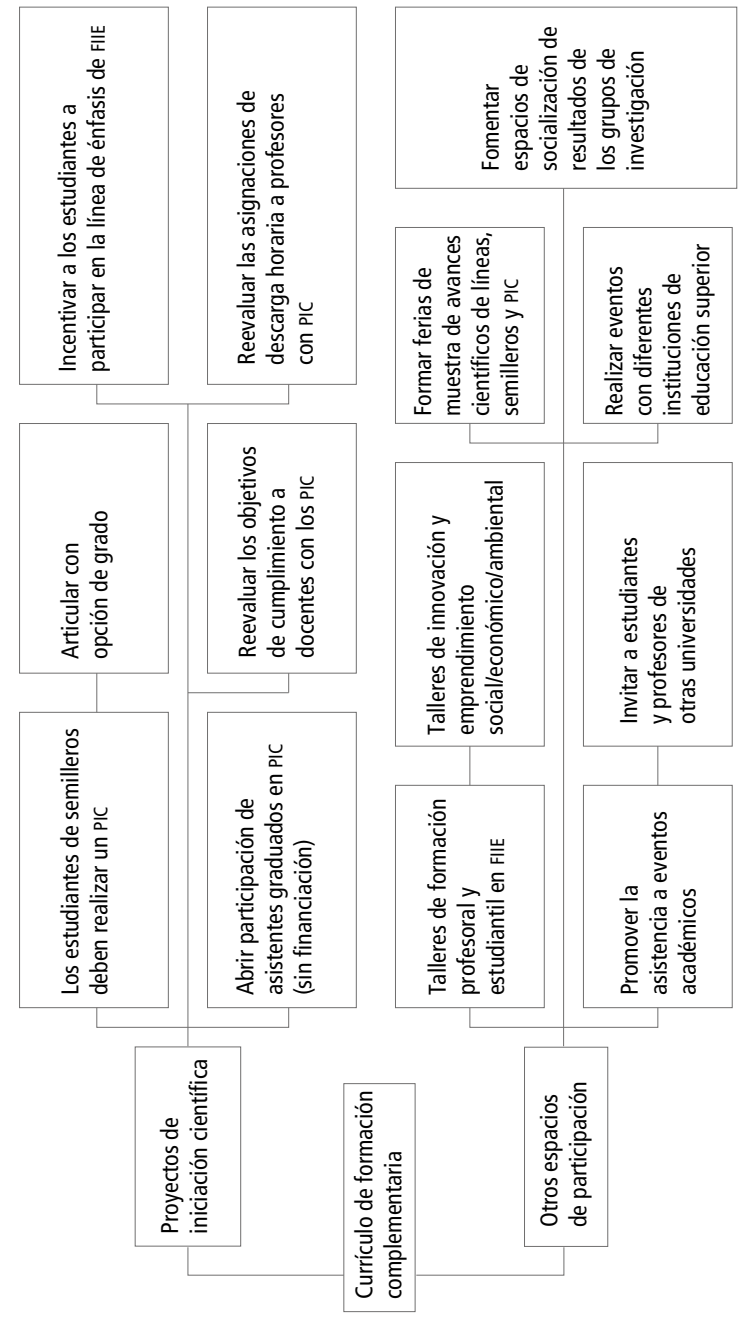




\subsection{Otras estrategias}

6.4.1 Línea de acción: monitoreo, seguimiento y evaluación de la política FIIE

Como parte fundamental de la presente política, se ve necesaria la aparición de un nuevo organismo en la Universidad, de carácter académico, con participación en los distintos grupos de interés que componen la UMNG, para poder monitorear, seguir y evaluar la ejecución de esta política. Así, se proponen las siguientes actividades:

- Fundar el observatorio de la cultura en investigación, innovación y emprendimiento de la UMNG, cuyas tareas consistirían en monitorear, evaluar y hacer seguimiento de la política.

- Elegir los delegados de los grupos de interés que compondrían el observatorio.

- Realizar un taller para definir los instrumentos y herramientas que utilizará el observatorio, conforme a sus tareas.

- Conformar mesas de trabajo con profesores, directores de programa y directores de centros de investigación para construir herramientas que permitan evaluar las competencias y habilidades que se fomentan desde la formación para la investigación, la innovación y el emprendimiento. 
6.4.2 Identificar espacios para el desarrollo de los talleres, actividades, lugares de encuentro y seguimiento para los estudiantes

Entre los espacios que se deben identificar, se encuentran:

- Lugares adecuados para el encuentro académico.

- Aulas para el desarrollo de clases interactivas.

- Laboratorios de innovación, Fablabs y Biolabs. 



\section{Bibliografía}

Ananiadou, K., y Claro, M. (2009). 21st Century Skills and Competences for New Millennium Learners in OECD Countries. EDU Working Paper N.o 41, 1-33.

Avvisati, F., Jacotin, G., y Vincent-Lancrin, S. (2013). Educating Higher Education Students for Innovative Economies: What International Data Tell Us. Tuning Journal of Higher Education, 223-240.

Rodríguez Durán, H. (2015). Plan Rectoral. La UMNG, un propósito común. Bogotá: Universidad Militar Nueva Granada.

Buol, P. (2009). Gestión por competencias. Diccionario de competencias. Recuperado de http://www.pablobuol. com/capacitacion/diccionario_de_competencias.htm

Colciencias. (2015). ¿Qué es un grupo de investigación? Recuperado de http://legadoweb.colciencias.gov.co/faq/ qu-es-un-grupo-de-investigaci-n

Colombia Aprende. (2009). Competencias comunicativas. Recuperado de http://www.colombiaaprende.edu.co/ html/competencias/1746/w3-article-243909.html Consejo Nacional de Acreditación (CNA). (2014). Acuerdo 03 de 2014. Por el cual se aprueban los lineamientos para la acreditación institucional. Bogotá: MEN. 
Consejo Nacional de Acreditación (CNA). (2010). Lineamientos para la acreditación de alta calidad de programas de maestría y doctorado. Bogotá: MEN.

Consejo Nacional de Educación Superior (CESU). (2016). Acuerdo 03. Lineamientos para acreditación de especialidades médicas. Bogotá: MEN.

Cruz, D. M., y Pfeifer, L. I. (2007). Contribuciones de la investigación científica a la formación profesional: ¿qué piensan los estudiantes de terapia ocupacional? Revista Chilena de Terapia Ocupacional, 7, 13-21.

Díaz, M. (2002). Flexibilidad y educación superior en Colombia. Bogotá: Icfes.

Drucker, P. (2002). The Discipline of Innovation. Recuperado de https://hbr.org/2002/08/the-discipline-of-innovation

Educar Chile. (2013). Competencia: iniciativa e innovación. Recuperado de http://ww2.educarchile.cl/userfiles/P0001/Image/pasion/file/competenciaD17.pdf

Fariñas D., María J. (2004). Globalización, ciudadanía y derechos humanos. Madrid: Dykinson.

Flecha, R., Gómez, J., y Puigvert, L. (2001). Teoría sociológica contemporánea. Barcelona: Paidós.

Freire, J., y Mora, L. (2009). Competencias informacionales e informáticas en el ámbito universitario. VII Jornadas CRAI, 4 y 5 de junio. 
Giones-Vals, A., y Serrat-Brustenga, M. (2010). La gestión de la identidad digital: una nueva habilidad informacional y digital. BID. Recuperado de http://eduteka.icesi. edu.co/gp/upload/giones2.pdf

González Cardona, D. A. (2017). Formación e investigación: balance de un campo en tensión. Actualidades Pedagógicas, 69, 277-294.

Guerrero Useda, M. (2007). Formación de habilidades para la investigación desde el pregrado. Acta Colombiana de Psicología, 10(2), 190-192.

Hernández, C. A. (2003). Investigación e investigación formativa. Nómadas, 183-193.

Herrera, A., y Didriksson, A. (1999). La construcción curricular: innovación, flexibilidad y competencias. Educación Superior y Sociedad, 10(2), 29-52.

Instituto Nacional de Estadística, Geografía e Informática. (2005). Curso de metodología de la investigación. Capacitación 2005. Ciudad de México: Instituto Nacional de Estadística, Geografía e Informática.

Jaimes Camacho, C. S. (2009). Los semilleros de investigación, una cultura de investigación formativa. En L. F. Molineros Gallón, Orígenes y dinámicas de los semilleros de investigación en Colombia. Popayán: Editorial Universidad del Cauca.

Jiménez, W. G. (2006). La formación investigativa y los procesos de investigación científico-tecnológica en la 
Universidad Católica de Colombia. Studiositas, 1(1), 45-52.

Kottow, M. (2011). La deliberación bioética. Praxis, Revista de Psicología, 13(19), 53-74.

Lizarazo Ruíz, P. E. (2015). Identificar y describir las competencias de liderazgo que requiere un comandante de unidad táctica a partir del reconocimiento de las voces de sus subalternos. Bogotá: Universidad Militar Nueva Granada.

Márquez González, C., Verdugo Lucero, J., Villareal Caballero, L., Montes Delgado, R., y Sigales Ruiz, S. (2016). Resiliencia en adolescentes víctimas de violencia escolar. International Journal of Developmental and Educational Psychology, 2, 485-498.

Martin Trust Center. (22 de febrero de 2017). Entrepreneurship: Why we need to keep calm and trust the process. Recuperado de http://entrepreneurship.mit.edu/ entrepreneurship-need-keep-calm-trust-process/

Ministerio de Educación Nacional (MEN). (2007a). Competencias de pensamiento lógico, crítico y creativo. Recuperado de sitios.educando.edu.do/.../competencia-pensamiento-logico-critico-y-creativo.docx Ministerio de Educación Nacional (MEN). (2007b). Flexibilización curricular. Recuperado de www.mineducacion. gov.co/1621/article-82793.html 
Ministerio de Educación Nacional (MEN). (s. f.). Currículo. Recuperado de https://www.mineducacion.gov.co/1621/ article-79413.html

Miyahira Arakaki, J. (2009). La investigación formativa y la formación para la investigación en el pregrado. Rev Med Hered, 20(3), 119-122.

Navarro Saldaña, G. (2015). Implementación del modelo educativo desde una perspectiva teórico-práctica. Aprendizaje de Macrocompetencias genéricas; aprendizaje significativo. En G. Navarro Saldaña, G. Vaccarezza Garrido, M. González Navarro y R. Catalán Velázquez, Construcción del conocimiento en educación superior. Concepción: Sello Editorial Universidad de Concepción.

Nicolescu, B. (1998). La transdisciplinariedad, una nueva visión del mundo. París: Du Rocher.

Nicolescu, B. (2013). La necesidad de la transdisciplinariedad en la educación superior. Trans-Pasando Fronteras, 3. Recuperado de https://www.icesi.edu. co/revistas/index.php/trans-pasando_fronteras/article/ view/1624

Parra Moreno, C. (2004). Apuntes sobre la investigación formativa. Educación y Educadores, 7, 57-77.

Pedroza Flores, R. (2005). La flexibilidad académica en la universidad pública. En R. Pedroza Flores y B. G. 
Briceño, Flexibilidad académica y curricular en las instituciones de educación superior. México: Porrúa. Posada Álvarez, R. (2004). Formación superior basada en competencias, interdisciplinariedad y trabajo autónomo del estudiante. Revista Iberoamericana de Educación, 1-33.

Restrepo Gómez, B. (2003). Conceptos y aplicaciones de la investigación formativa, y criterios para evaluar la investigación científica en sentido estricto. Consejo Nacional de Acreditación.

Restrepo Gómez, B. (2006). Tendencias actuales en la educación superior: rumbos del mundo y rumbos del país. Revista Educación y Pedagogía, 18(46), 79-90. Scott, A. (Mayo 30 de 2012). Innovation Is a Discipline, Not a Cliché. Recuperado de https://hbr.org/2012/05/ four-innovation-misconceptions

Scott, R., y Vincent-Lancrin, S. (2014). Educating Innovators and Entrepreneurs. En The Global Innovation Index 2014.

Sierra, C. (2006). Competencias cognitivas. Recuperado de cmap.upb.edu.co/rid=1145897240765...924/COMPETENCIAS_COGNITIVAS.ppt

Sturgess, G. (2012). Skill vs. Competencies. What's the difference? Recuperado de http://www.talentalign.com/ skills-vs-competencies-whats-the-difference/ 
Torrelles, C., Coiduras, J., Isus, S., Carrera, F., París, G., y Cela, J. (2011). Competencia de trabajo en equipo: definición y categorización. Profesorado. Revista de Currículum y Formación del Profesorado, 15(3), 329-344.

Torres, J. (2006). Globalización e interdisciplinariedad en el currículo integrado. Madrid: Morata.

Universidad Militar Nueva Granada. (2009a). Proyecto Educativo Institucional 2009. Bogotá: Universidad Militar Nueva Granada.

Universidad Militar Nueva Granada. (2009b). Sistema de Ciencia, Tecnología e Innovación. Bogotá: Universidad Militar Nueva Granada.

Universidad Militar Nueva Granada. (2013a). Acuerdo 08 de 2013. Bogotá: Universidad Militar Nueva Granada.

Universidad Militar Nueva Granada. (2013b). Plan de Desarrollo Institucional 2009-2019. Balance primera fase 2009-2012. Segunda fase 2013-2016. Bogotá: Universidad Militar Nueva Granada.

Zabala, A., y Arnau, L. (2014). Métodos de investigación del medio. Concepción del aprendizaje: principios psicopedagógicos. En A. Zabala y L. Arnau, Métodos para la enseñanza de las competencias. Barcelona: Editorial GRAO. 



\section{Agradecimientos}

La presente política contó con la valiosa asesoría de directivos, docentes y funcionarios de la Universidad, así como de consultores externos. Se mencionan a continuación: Leivy Yamile Barón Díaz, División de Investigaciones; Luisa Fernanda Contreras, División de Desarrollo Tecnológico e Innovación; Mario Alejandro Castro, División de Investigación e Innovación; Ricardo Gutiérrez, Facultad de Ingeniería; Blanca Aurora Pita y Nohora Joya, Facultad de Educación y Humanidades; Yenni Viviana Duque, Facultad de Ciencias Económicas; Liliana Franco, Carlos Andrés Coy y Fernando Cantor Rincón, Facultad de Ciencias Básicas y Aplicadas, y Fabio Colmenares Burgos y Carlos Monroy, Ecosocial Consultores S. A. S.

Por último, se destaca la contribución de grupos de profesores, estudiantes, directores de centros de investigación, decanos y directivos que participaron en la construcción de la presente política. 

Política FIIE

pertenece a la Colección Literatura Gris, serie White Papers, editada por la Editorial Neogranadina de la Universidad Militar Nueva Granada. El texto fue compuesto con tipos ITC Century std y se terminó de imprimir en Xpress Estudio Gráfico y Digital, en la ciudad de Bogotá, en diciembre del año 2018. 

La Vicerrectoría de

Investigaciones de la UMNG construyó una política de formación para la investigación, la innovación y el emprendimiento.

\section{IMPORTANCIA DE LA POLÍTICA FIIE}

F — Formación. La umng tiene como objetivo ser un referente en investigación científica con repercusión en el triángulo de universidad-empresa-Estado. La política FIIE surge para fortalecer la relación existente entre formación e investigación.

I - Investigación. Permite la inmersión en la lógica y las prácticas de la investigación científica, de modo que el nuevo conocimiento que se genere, se apropie, y se aplique en diferentes contextos.

I - Innovación. Da las herramientas para buscar, descubrir y desarrollar nuevas oportunidades, a través de modelos de implementación.

E - Emprendimiento. Asume las iniciativas de cambio desde la perspectiva del líder, que busca el logro de objetivos definidos, gestiona riesgos y genera prácticas sistemáticas para innovar.

\section{CULTURA DE LA INVESTIGACIÓN, LA INNOVACIÓNY EL EMPRENDIMIENTO}

La política fIIE busca crear una cultura. Es decir, un conjunto de prácticas, acciones, significados, disposiciones y directrices que se interiorizan, reproducen y manifiestan de forma colectiva, $\mathrm{y}$ que determinan el comportamiento institucional hacia la investigación, para desarrollar la producción de conocimiento científico y académico, y para formar investigadores y profesionales que promuevan la innovación y el emprendimiento. 
Comunica, interpreta y se expresa científicamente.

Piensa de manera lógica, crítica y argumentada.

\section{Conoce las bases \\ teóricas de la \\ investigación científica}

y sus métodos.

Sabe inglés.

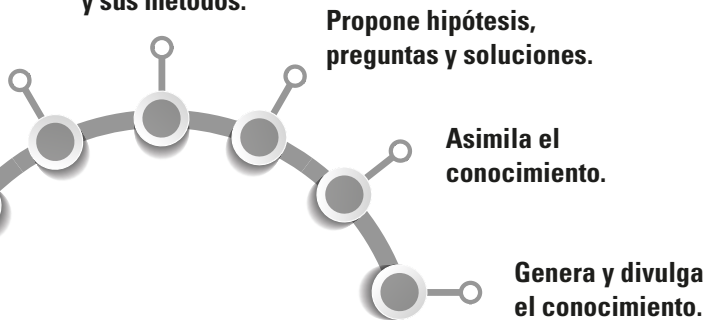

Propone hipótesis, preguntas y soluciones. el conocimiento.
Las competencias y

habilidades no son un set

de requisitos que debe

reunir el estudiante.
Son cualidades que los individuos descubren y desarrollan en su proceso de formación.

\section{Empatía para construir relaciones interpersonales.}

\section{Disposición para enfrentar problemas y buscar soluciones.}

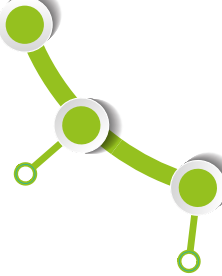

Formúla nuevos proyectos, considerando su ejecución y sostenibilidad.

\section{Identifica} necesidades y se plantea cómo satisfacerlas.
Intercambia información y puntos de vista para trabajar en colaboración.

Reconoce la importancia del liderazgo para coordinar un equipo de trabajo. 
EL

cURBículo

SABE
El currículo sabe resignifica

el proceso de formación

profesional de la

universidad y es el eje que articula la política fiie, conjugando cuatro dimensiones.

\section{DIMENSIONES DEL SABE}

$\mathbf{S} \longrightarrow$ SOCIOLÓGICA

La sociedad es el engranaje donde emergen las dinámicas y las transformaciones culturales.

\section{A $\longrightarrow$ antropológica}

El ser humano es el origen de toda formulación y proyecto curricular.

\section{$\mathbf{B} \longrightarrow$ BIOÉTICA}

Es el saber que ayuda a comprender las dinámicas relacionales entre hombre, naturaleza y medio ambiente, y también aquello relacionado con la vida y lo que la preserva y cuida.

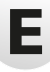

\section{EPISTEMOLÓGICA}

Es el conjunto de ciencias, saberes y conocimientos que responden a las exigencias de la sociedad y del hombre.

El currículo SABE es una apuesta que va más allá de la transmisión de conocimiento. En sus dimensiones se agrupan las habilidades, las competencias y los desempeños descritos.
Todo programa y plan de estudios de la universidad, debe considerar las dimensiones del SABE y su impacto en la FIIE. 
SABE, en cuanto currículo de formación para la investigación, la innovación y el emprendimiento, determina unas líneas fundamentales el macrocurrículo, mesocurrículo, microcurrículo y currículo de formación complementaria. Esas líneas tienen unos enfoques que permiten la flexibilidad curricular.

\section{Interdisciplinariedad}

Cooperación de varias disciplinas

Multidisciplinariedad

Diversidad de enfoques 0 puntos de vista

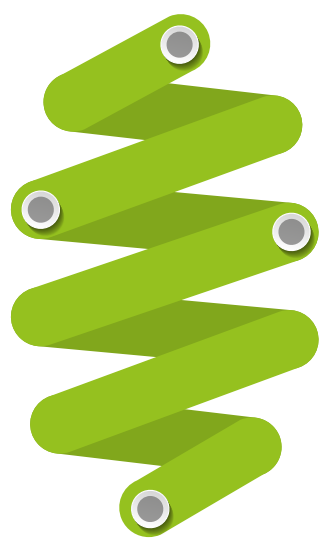

Transdisciplinariedad Conocimiento que cruza diferentes disciplinas

La flexibilidad curricular favorece la movilidad de los actores universitarios y construye un escenario propicio para la investigación, la innovación y el emprendimiento. 


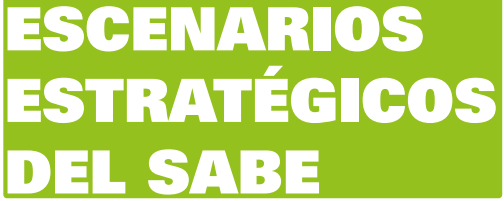

La función curricular principal de la educación superior es la investigación. Alrededor de esto, el currículo SABE tiene unas líneas que se articulan: macrocurrículo, mesocurrículo, microcurrículo y currículo de formación complementaria.

\section{MACROCURRÍCULO}

Escenario en el que se identifican los problemas socioculturales, antropológicos y bioéticos, y se formulan probables soluciones desde la perspectiva particular de cada área del conocimiento.

\section{- MESOCURRÍculO}

Escenario en el que se articulan los propósitos establecidos en el macrocurrículo y se establece la flexibilidad curricular, junto con su ejecución real. Es el programa académico de un área, con sus respectivas habilidades y competencias.

- MICROCURRÍcULO

Escenario donde se produce el hecho educativo, la enseñanza y el aprendizaje, es decir, donde se encuentran el profesor y el estudiante. Este encuentro está dinamizado por la formulación de los programas y las actividades de los cursos.

\section{CURRÍCULO DE FORMACIÓN COMPLEMENTARIA}

Escenario que brinda propuestas de formación complementaria. No hace parte de la propuesta formal del mesocurrículo y microcurrículo, aunque responde a un plan institucional para fomentar la creatividad, la innovación y el espíritu crítico de los estudiantes y profesores. 


\section{OBJETIVOS POR \\ LINEAAS DEL SABE}

\section{○ MESOCURRÍcULO}

Crear en los planes de estudios espacios para asegurar el desarrollo transversal de habilidades, competencias y desempeños de investigación, innovación y emprendimiento.

$\longrightarrow$ Los cursos deben ser ofrecidos en todos los programas, bajo dos modalidades: cursos específicos y cursos electivos complementarios.

\section{- 0 MICROCURRÍCULO}

Incursionar en metodologías de aprendizaje por construcción y descubrimiento en el aula, que ayuden a fortalecer las competencias y habilidades en las asignaturas del plan de estudios.

$\longrightarrow$ Construir vínculos curriculares entre asignaturas, especialmente en los primeros semestres, en donde puedan reunirse grupos multidisciplinares y aunarse esfuerzos entre diversos cursos para asegurar una transversalidad de la formación para la investigación.

\section{○ CURRÍCULO DE FORMACIÓN COMPLEMENTARIA}

- Uno de los objetivos en este escenario es promover el desarrollo de los semilleros de investigación, cuyas fases permiten desarrollar habilidades y competencias, por ejemplo, el pensamiento lógico y la conciencia de la responsabilidad ética y social.

\section{ETAPAS DE LA FORIMACIÓN PARA LA INVESTIGACIÓN}

\section{- 1. Fundamentación de la investigación}

Identificación del estado del arte de la investigación abordada

2. Exploración

Construcción del anteproyecto de la investigación

3. Implementación de la investigación

Vinculación a un proyecto de iniciación científica (PIC)

4. Divulgación

Finalización del PIC

Producción de un artículo o ponencia

Presentación de los trabajos producidos 


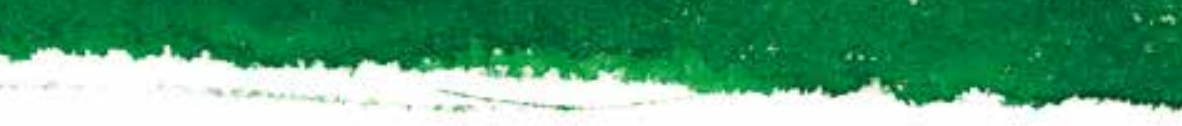

La investigación es fundamental en el proceso de formación profesional. En este sentido, la investigación formativa da las herramientas para adquirir conocimientos en un determinado campo del saber. Sin embargo, también es necesario pensar la investigación de manera transversal a las áreas del conocimiento. Con este interés, se construyó la presente política de formación para la investigación, la innovación y el emprendimiento, con un enfoque curricular que busca desarrollar en la comunidad académica habilidades, competencias y desempeños que se requieren para apropiar conocimientos y generarlos en la sociedad. 